\title{
THE ANNUAL MEETING OF THE SOCIETY
}

The fifty-fourth Annual Meeting of the American Mathematical Society was held at the University of Georgia, Athens, Georgia, Monday to Wednesday, December 29-31, 1947, in conjunction with the Annual Meeting of the Mathematical Association of America. Over two hundred persons registered, including the following one hundred eighty-four members of the Society:

Louise Adams, V. W. Adkisson, R. P. Agnew, G. E. Albert, C. B. Allendoerfer, W. F. Atchison, E. A. Bailey, D. F. Barrow, E. F. Beckenbach, W. S. Beckwith, E. G. Begle, R. G. Blake, L. M. Blumenthal, M. G. Boyce, H. J. Bradley, J. W. Bradshaw, A. T. Brauer, H. E. Bray, Foster Brooks, N. R. Bryan, R. S. Burington, L. P. Burton, L. E. Bush, S. S. Cairns, Iris Callaway, E. A. Cameron, C. C. Camp, W. B. Carver, Alonzo Church, Randolph Church, R. V. Churchill, C. E. Clark, F. E. Clark, J. M. Clarkson, A. C. Cohen, Eckford Cohen, L. W. Cohen, E. C. Coker, J. B. Coleman, L. P. Copeland, N. A. Court, R. R. Coveyou, W. H. H. Cowles, H. B. Curry, J. H. Curtiss, C. H. Denbow, A. H. Diamond, J. M. Dobbie, H. H. Downing, W. L. Duren, L. A. Dye, E. D. Eaves, F. A. Ficken, L. R. Ford, Tomlinson Fort, J. S. Frame, H. K. Fulmer, A. S. Galbraith, H. M. Gehman, M. E. Gillis, Wallace Givens, Casper Goffman, H. E. Goheen, V. D. Gokhale, J. S. Gold, Michael Goldberg, M. O. González, W. H. Gottschalk, S. H. Gould, Fletcher Gray, D. E. Green, R. E. Greenwood, W. C. Griffith, William Gustin, D. W. Hall, E. A. Hedberg, G. A. Hedlund, G. W. Hess, E. H. C. Hildebrandt, T. H. Hildebrandt, Einar Hille, G. B. Huff, W. R. Hutcherson, L. C. Hutchinson, M. P. Jarnagin, Jr., E. D. Jenkins, F. B. Jones, H. T. Karnes, A. J. Kempner, D. E. Kibbey, J. R. Kline, F. W. Kokomoor, H. L. Krall, S. H. Lachenbruch, A. E. Landry, G. B. Lang, G. A. Larew, E. H. Larguier, C. G. Latimer, H. L. Lee, T. H. Lee, Solomon Lefschetz, R. J. Levit, D. C. Lewis, F. A. Lewis, R. A. Lytle, Dorothy McCoy, E. J. McShane, C. C. MacDuffee, E. L. Mackie, J. D. Mancill, Szolem Mandelbrojt, W. A. Martin, W. T. Martin, L. E. Mehlenbacher, B. E. Meserve, H. A. Meyer, A. N. Milgram, D. D. Miller, R. A. Miller, T. W. Moore, W. B. Moye, S. L. Nelson, P. F. Nemenyi, F. H. Murray, C. V. Newsom, E. B. Ogden, Morris Ostrofsky, E. R. Ott, F. W. Owens, H. B. Owens, W. V. Parker, I. E. Perlin, B. J. Pettis, H. B. Phillips, Harry Polachek, G. B. Price, R. C. Prim, F. M. Pulliam, J. F. Randolph, A. S. Rayl, L. M. Reagan, Mina Rees, P. K. Rees, P. R. Rider, R. F. Rinehart, L. A. Ringenberg, E. K. Ritter, J. H. Roberts, H. A. Robinson, L. V. Robinson, W. J. Robinson, A. C. Schaeffer, E. B. Shanks, T. M. Simpson, C. B. Smith, H. L. Smith, P. A. Smith, W. S. Snyder, E. P. Starke, R. P. Stephens, R. W. Stokes, J. L. Synge, Otto Szász, Olga Taussky-Todd, J. S. Taylor, H. P. Thielman, J. M. Thomas, H. S. Thurston, E. W. Titt, H. C. Trimble, G. R. Trott, C. A. Truesdell, Henry Van Engen, A. H. Van Tuyl, T. L. Wade, A. D. Wallace, J. A. Ward, F. P. Welch, W. F. Whitmore, G. T. Whyburn, W. L. Williams, R. L. Wilson, L. C. Young.

Sessions for reading contributed papers were held at 2:00 P.M., Monday, at 10:00 A.M. and 3:15 P.M., Tuesday, and at 3:15 P.M., Wednesday. The presiding officers for these sessions were Professors 
Tomlinson Fort, L. R. Ford, S. S. Cairns, T. H. Hildebrandt, G. T. Whyburn, and G. A. Hedlund.

The twenty-first Josiah Willard Gibbs Lecture was given on Monday evening by Professor P. M. Morse of the Massachusetts Institute of Technology and the Brookhaven National Laboratories on Mathematical problems in operations research. President Einar Hille presided.

On Tuesday afternoon with Vice President L. R. Ford presiding, Professor E. F. Beckenbach of the University of California at Los Angeles delivered an address entitled Convex functions.

The annual business meeting and election of officers was held on Wednesday morning, President Einar Hille presiding. The proceedings are included later in this report. At the close of the business session Professor T. H. Hildebrandt of the University of Michigan delivered his retiring presidential address on Integration in abstract spaces. Following Professor Hildebrandt's address those members of the Committee on Reorganization who were present at the meeting outlined some of the problems which the committee faces and asked for suggestions from the members present.

Sessions of the Mathematical Association of America were held on Thursday morning and afternoon.

On Monday morning and afternoon tours were conducted for mathematicians to some of the antebellum homes in Athens. On Tuesday afternoon a tea and reception for the guests of the University was held in Lyndon Hall. On Tuesday evening a concert was given in the University Chapel by members of the Department of Music. A special art exhibit for those attending the meetings was held on Wednesday afternoon in the Fine Arts Building.

At the dinner on Wednesday evening for mathematicians and their guests, Professor Tomlinson Fort of the University of Georgia was toastmaster. President H. W. Caldwell of the University of Georgia gave an address of greeting. Music was provided by Messrs. James Griffith and Byron Warner. The following addresses were presented: What is applied mathematics?, Professor J. L. Synge of Carnegie Institute of Technology; Applied mathematics in government service, Dr. J. H. Curtiss of the National Bureau of Standards; Applied mathematics in the college and university, Professor Emeritus H. B. Phillips of the Massachusetts Institute of Technology. These were followed by a dramatic skit entitled Applied mathematics, presented by members of the Department of Mathematics of the University of Georgia. Professor R. P. Agnew of Cornell University presented resolutions expressing the thanks and appreciation of the members of 
the Society and of the Association to the various groups at the University of Georgia for the excellent arrangements made for the meeting.

At the meeting of the Board of Trustees at 6:00 P.M. on December 29, 1947, in Snelling Hall, there was no quorum present and the Board adjourned to January 17, 1948.

At this meeting of the Board of Trustees the resignations of Professor G. W. Mullins and Dr. Warren Weaver as members of the Board of Trustees were presented and accepted with regret. The following resolutions were adopted by the Trustees regarding the significant contributions of Professor Mullins and Dr. Weaver to the work of the Society:

Professor George Walker Mullins of Columbia University has resigned from the Board of Trustees of the American Mathematical Society after nearly twenty years of signal service as Treasurer and Trustee. This period coincided with one of distinguished usefulness to the University where he was notably influential in formulation of policies. Happy relations between Columbia University and the Society began with its founding by Professor Fiske sixty year ago. Through the good offices of Professor Mullins these relations became ever more cordial and the University ever more generous in its attitudes.

The present favorable status of the financial affairs of our Society is in no small measure due to our colleague's devotion and skill. The Board is profoundly appreciative of all these services, and tenders to him its heartiest good wishes.

It is not possible to record in a few paragraphs the qualities of mind and spirit that have made the work of Dr. Warren Weaver, as a Trustee of the American Mathematical Society, so successful and outstanding and so satisfying to his associates on the Board. During his seven years of service as a Trustee, he has given generously of his time and effort in trying to solve the many perplexing problems that constantly arose during this period of expansion. Equipped with a liberal mind of dignity and real distinction, he brought to the discussion of any problem that degree of human tolerance and understanding so necessary in the guidance of the affairs of the Society.

Beginning with 1933 Dr. Weaver, realizing that science was being misdirected in some regions of Europe, was a powerful factor in recruiting for American mathematics a large number of scholars from the various European countries, thus enriching on a widespread and national scale the several branches of our subject. His statesmanlike assistance in founding Mathematical Reviews is only one of the more obvious of the outcomes of his services. His initiative in the establishment of pre-doctoral fellowships for young men who had been diverted from their studies through scientific work for the war effort will result in a lessening of the alarming gap in personnel which threatens education and research.

As Chief of the Applied Mathematics Panel of the National Defense Research Committee during World War II, Dr. Weaver rendered signal service. Through his insight and diplomatic skill, he was able to convince the armed forces that mathematics is vital in the solution of many urgent problems of defense and offense. In the various events which resulted in mathematics emerging from the war with greatly enhanced prestige, he was a notable leader.

Dr. Weaver's vision of the future concerning the part that mathematics may play 
in American civilization will be greatly missed in the deliberations of the Trustees, but it is the good fortune of the Board that his advice and help will still be available.

The Council met at 8:00 P.M. on December 30 at the home of Professor Tomlinson Fort.

The Secretary announced the election of the following seventy-one persons to ordinary membership in the Sociey:

Professor Maria Yolanda de Mello Nogueria Abdelhay, University of Brazil;

Mr. E. Leonard Arnoff, Case Institute of Technology;

Mr. Leon Auerbach, Gallaudet College, Washington, D. C.;

Mr. Edwin Ward Banhagel, Physics Department, Wayne University;

Professor Otakar Borûvka, Masaryk University, Brno, Czechoslovakia;

Mr. George Bott, Operations Evaluation Group, Navy Department, Washington, D.C.;

Miss Thelma Elizabeth Bradford, Claflin University, Orangeburg, S. C.;

Mr. João Augusto Breves Filho, University of São Paulo;

Mr. Rudolph Richard Caputo, Naval Shipyard, Brooklyn, N. Y.;

Mr. Phillip George Carlson, Jr., Rensselaer Polytechnic Institute;

Mr. Eric R. I. Carson, St. Francis College, Brooklyn, N. Y.;

Professor Alonzo Clifford Cohen, Jr., University of Georgia;

Mr. Louis M. Court, Rutgers University;

Mr. William Francis Dice, St. Francis College, Brooklyn, N. Y.;

Mr. Alexander Weaver Ebin, American Institute of Man, Chicago, Ill.;

Mr. Jason Arundel Ellis, State University of Iowa;

Mr. John Fall, Acquisition Division, New York Public Library;

Mr. Athanasius Floris, Pacific Electric Railway Co., Los Angeles, Calif.;

Professor Luiz Barros Freire, Department of Physics, University of Recife, Recife,

Pernambuco, Brazil;

Mr. Marcos Galper, Rio de Janeiro, Brazil;

Mr. Harold Grad, New York University;

Mr. Ross Edwin Graves, University of Minnesota;

Mr. Fletcher Gray, Birmingham, Ala.;

Miss Dorothy Eunice Green, Huntingdon College, Montgomery, Ala.;

Dr. Edwin Leland Harder, Westinghouse Electric Corporation, East Pittsburgh, Pa.;

Mr. Keith Ortlepp Househam, Princeton University;

Mr. Albert Charles Howell, Actuarial Department, John Hancock Mutual Life Insurance Co., Boston, Mass.;

Mr. Roy Sherman Kingsbury, Operations Evaluation Group, Navy Department, Washington, D. C.;

Professor Walter Eddie Koss, Agricultural and Mechanical College of Texas;

Professor Julien Kravtchenko, University of Grenoble, Grenoble, France;

Mr. Maurice Albert L'Abbe, Princeton University;

Professor Friedrich Wilhelm Levi, Tata Institute of Fundamental Research, Bombay, India;

Mr. Samuel Levy, National Bureau of Standards, Washington, D. C.;

Brother George Lewis, La Salle College, Philadelghia, Pa.;

Sister Mary Teresine Lewis, Fontbonne College, St. Louis, Mo.;

Mr. Geraldo dos Santos Lima Filho, University of São Paulo;

Mr. Clair George Maple, Carnegie Institute of Technology;

Mr. Gerald W. L. Van Douglas Martynes, Rio de Janeiro, Brazil;

Professor Ross Raymond Middlemiss, Washington University;

Mr. Warren Keith Moore, University of Kansas; 
Professor Abrahão de Moraes, University of São Paulo;

Sister Charles Anne Mulligan, Albertus Magnus College, New Haven, Conn.;

Professor Francisco Antonio Lacaz Netto, University of São Paulo;

Mr. William Alfred Nichols, Canadian Broadcasting Corporation, Montreal, Canada;

Dr. Yves Nubar, New York University;

Miss Thelma Eve Peacock, Wells College;

Mr. Chester Clement Piersol, Naval Gun Factory, Washington, D. C.;

Mr. Johnny Webster Ponds, West Virginia State College;

Mr. Robert Clay Prim, 3rd, Naval Ordnance Laboratory, White Oak, Md.;

Professor Ary Norton de Murat Quintella, Military Academy, Rio de Janeiro, Brazil;

Mr. Robert Abram Roberts, West Virginia University;

Professor Plinio Sussekind Rocha, University of Brazil;

Mr. Milton Edward Rose, Irvington, N. J.;

Miss Rose Lee Rowen, Operations Evaluation Group, Navy Department, Washington, D. C.;

Miss Leila Raines Rubashkin, Cornell University;

Mr. Bernard Sachs, Polytechnic Institute of Brooklyn;

Mr. Anthony Henry Sarno, St. John's University;

Mr. Jacob T. Schwartz, New York, N. Y.;

Mr. George Shapiro, Brooklyn College;

Dr. Jack Sherman, Research Laboratory, The Texas Company, Beacon, N. Y.;

Sister Mary Carmel Sullivan, Albertus Magnus College, New Haven, Conn.;

Mr. John Joseph Taylor, Bendix Aviation Corporation, Teterboro, N. J.;

Mr. Affonso Penteado de Toledo Piza, State Department of Statistics of São Paulo, São Paulo, Brazil;

Dr. Francis Eligius Van Bergen, Atheneum St. Nicolas-Waas, Belgium;

Visiting Professor Bartel Leendert van der Waerden, The Johns Hopkins University;

Professor Rin Wang, Changbai Normal College, Babaerun, Kirin, China;

Mr. Gerard Washnitzer, Brooklyn, N. Y.;

Mr. Daniel Robson Waterman, Brooklyn College;

Dean Cecil Lamborn Woods, Pacific Union College, Angwin, Calif;

Mr. John Leonard Yarnell, Topeka, Kan.;

Mr. Philipp Wolfgang Zettler-Seidel, Naval Ordnance Laboratory, White Oak, Md.

It was reported that the following one hundred forty-six persons had been elected to membership on nomination of institutional members as indicated:

University of Alabama: Messrs. Richard Earl Allen and Henry Conrad Miller;

Brooklyn College: Mr. Leon H. Herbach;

Brown University: Messrs. Peter Chiarulli and Morton Finston, Dr. James Arthur Krumhansl, Miss Jacqueline Lydie Penez, Dr. Rohn Truell;

Bryn Mawr College: Miss Joan Elizabeth Robinson;

University of California: Messrs. John Gurland, Terry Allen Jeeves and Edward Silverman;

University of California at Los Angeles: Messrs. John David Newburgh and Lawrence Theodore Ratner;

The Case Institute of Technology: Mr. Francis Dunbar Parker;

University of Cincinnati: Mr. Nelson Paul Yeardley;

City College of the College of the City of New York: Messrs. Jerome Berkowitz, Irwin Fischer, Milton Martin Gutterman, Samuel Linial, John Jay Stachel and Herman Zabronsky; 
Columbia University: Messrs. Edward Kenneth Blum, Kuo-Tsai Chen and Arnold Lionel Fass, Miss Alice Osterberg, Messrs. Jack Maynard Patterson and Sherman Kopald Stein;

Cornell University: Messrs. George Laush and Walter Lynn Murdock, Miss Maria Alice Weber;

Duke University: Messrs. Samuel Wilfred Hahn and Thomas Davies Reynolds;

Equitable Life Insurance Company: Mr. Kermit Lang;

Harvard University: Messrs. Richard Eliot Chamberlin, Frederic Cunningham, Horace Chandler Davis, Paul Roesel Garabedian, Thomas Andrew Lehre, Peter MacNair, Jerome Joseph Newman, Henry Otto Pollak and Morton Lincoln Slater, Miss Dorothy Browne Shaffer, Mr. (William) Forrest Stinespring;

Illinois Institute of Technology: Messrs. Harold Greenspan, Louis Joseph, Donald Williamson Pounder and David Rubinfien, Dr. Herbert A. Simon, Miss Barbara Reese Vogel;

University of Illinois: Mr. James Bercos, Miss Marie Louise Boddy, Mr. George Truett Cates, Miss Lois Vivian Cline, Messrs. Cevdet A. Erzen, Albert Ansell Gopaul and Clemens Bernard Hanneken, Miss Ruth Heinsheimer, Messrs. Richard Edwin Janssen, Richard Lynn Mentzer, Leland Latham Scott, Joe Willie Wray;

Indiana University: Mr. Israel Nathan Herstein;

Institute for Advanced Study: Drs. Alfons Maria Frans Borgers and Hel Braun, Professor Marie Radegoude Jeanne Charpentier, Dr. Kien-Kwong Chen, Professor Hubert Delange, Drs. Erling F $\phi$ lner, Harish-Chandra, Nicolaas Hendrik Kuiper, Jean Mariane, Szu-Hoa Min and Paolo Nesbeda, Professor Ake Vilhelm Carl Pleijel, Dr. Atle Selberg;

Iowa State College of Agriculture and Mechanic Arts: Mr. Carl Eric Langenhop;

The Johns Hopkins University: Messrs. Arthur Simpson Littell, Henry Llewellyn Merritt, Arthur Stein, Mitchell Trauring, Mathews C. Waddell, and Arthur Wouk;

Lehigh University: Messrs. Wilbur Hibbard and Ralph Waldo Young;

University of Maryland: Mr. Arnold George Rawling;

Massachusetts Institute of Technology: Messrs. John Bertram Giever, John Beckwith Kelly, Warren Paul Manger, Oliver Gordon Selfridge;

University of Michigan: Miss Marjorie Lee Browne, Messrs. Bertram Joseph Eisenstadt, Kenneth Arthur Fowler, Meyer Jerison, Benjamin Lapidus, Clay Lamont Perry, Jr., and David Van Vranken Wend;

Michigan State College: Mr. Jean Joseph LeJunter;

University of Minnesota: Messrs. Watson Bryn Fulks, Jack Indritz and Chih-yi Wang;

New York University: Miss Anneli Leopold;

Northwestern University: Mr. Lester Gothard Riggs;

University of Notre Dame: Mr. John Charles Burke;

Ohio State University: Messrs. Joseph Elliott Adnew, Jr., Byron Brown Dressler and George Marsaglia;

Oklahoma Agricultural and Mechanical College: Mr. Crosman Jay Clark;

University of Oregon: Mr. Walter Mossman Gilbert;

Pennsylvania State College: Messrs. Stephen Jerome Bilo and Robert Taylor Foote; University of Pennsylvania: Misses Leila Ann Dragonette and Anne Marie Whitney;

Rice Institute: Mr. Neville Carter Hunsaker;

University of Rochester: Mr. William Anderson;

The College of St. Thomas: Mr. Ferdinand Roy Ohnsorg; 
Smith College: Miss Evelyn Boyd;

Swarthmore College: Mr. Robert Garlin Kuller;

Syracuse University: Miss Elizabeth Harriet Wetherell;

University of Tennessee: Mr. William Austin Rutledge;

University of Texas, Department of Pure Mathematics: Mr. Mark Hall Clarkson, Miss Mary Ellen Estill, Mr. John Sheridan MacNerney;

University of Toronto: Messrs. Kenneth Dudley Fryer and Atholl Livingstone Wilson;

University of Washington: Messrs. Fred C. Andrews and James L. Hildebrandt;

Wellesley College: Mrs. Elaine Van Aken Cowen;

University of Wisconsin: Messrs. Howard Ernest Campbell, Kermit Howard Carlson, Marion Preston Emerson, Gerald Paul Dinneen, Delbert Ray Fulkerson, Leonard Eugene Fuller, Rodney Taber Hood, and John E. McAdam, Miss Ida Merle Mitchell, Messrs. Vernon Hugh Ross and Herbert Ruderfer;

Yale University: Messrs. Robert Goodell Brown, Jack Clark Gibson, John McGaughey Heath, William Gordon Lister, John Edward Lancelot Peck, Donald Aubry Quarles, Jr., and John Newton Williams.

The Secretary announced that the following had been admitted to the Society in accordance with reciprocity agreements with various mathematical organizations: London Mathematical Society: Dr. Hermann Kober, University of Birmingham, Birmingham, England; Dr. Robert Alexander Rankin, Cambridge University, England; Société Mathématique de France: Mr. Paul Belgodère, Centre National de la Recherche Scientifique, Paris; Dr. Gustave Choquet, Université de Grenoble; Professor Jean Alexandre Dieudonné, Faculté des Sciences de Nancy; Mr. Victor Dana, Faculty of Science, Cairo, Egypt; Professor Paul Jacques Dubreil, Faculté des Sciences, L'Université de Paris; Professor Luc Edmond Nicolas Gauthier, University of Nancy; Professor Gaston Maurice Julia, Ecole Polytechnique, Paris; Dr. Marc Krasner, Centre National de la Recherche Scientifique, Paris; Professor Paul Métral, Lycée de Marseille; Professor André Metté, Lycée Pasteur, Neuilly; Professor Victor Michel JeanMarie Thebault, Ecole Normale, Tennie; Swiss Mathematical Society: Professor Walter Nef, University of Fribourg, Fribourg, Switzerland; Unione Matematica Italiana: Professor Enrico Bompiani, University of Rome; Professor Mauro Picone, University of Rome.

It was reported that the Council had voted by mail: to accept the recommendation of the Committee on Applied Mathematics that the Second Symposium on Applied Mathematics be held at Massachusetts Institute of Technology during the summer of 1948; to authorize and request the President to appoint a committee to nominate two candidates for the vacancy in the Policy Committee for Mathematics, to occur on December 31, 1947; to accept the recommendation of the Emergency Committee for the International Congress of Mathe- 
maticians that steps be taken at once to nominate and elect officers and committees for the Congress; to authorize and request the President to appoint a committee to nominate officers and committees for the International Congress. It was also reported that the Council, by mail vote, had elected Professor Einar Hille as a representative of the Society on the Policy Committee for Mathematics, to succeed Professor T. H. Hildebrandt and to serve for a period of four years beginning January 1, 1948.

The Secretary is pleased to report at this time that the ordinary membership of the Society is now 3494, including 321 nominees of institutional members and 58 life members. There are also 103 institutional members. The total attendance at all meetings in 1947 was 1950; the number of papers read was 511 ; there were 12 hour addresses, 2 symposium addresses, 4 addresses and 21 papers at the Applied Mathematics Symposium, 1 Gibbs Lecture, 4 Colloquium Lectures, and 1 Retiring Presidential Address; the number of members attending at least one meeting was 1191.

The following appointments by President Einar Hille of representatives of the Society were reported: Professor R. P. Agnew at the inauguration of Katherine Gillette Blyley as President of Keuka College on October 4, 1947; Professor Einar Hille at the Convocation of the Sheffield Scientific School on October 17, 1947; Professor L. M. Kells at the inauguration of John Spangler Kieffer as President of St. John's College on October 25, 1947; Professor W. L. Miser at the inauguration of Charles Spurgeon Johnson as President of Fisk University on November 6-8, 1947; Professor M. H. Martin at the inauguration of Lowell Skinner Ensor as President of Western Maryland College on November 8, 1947; Professor C. B. Wright at the inauguration of James Gilliam Gee as President of East Texas State Teachers College on November 15, 1947; Professor G. T. Whyburn at the inauguration of Frank Bell Lewis as President of Mary Baldwin College on November 18, 1947.

The following additional appointments by the President were reported: Professors M. H. Stone (Chairman), R. P. Agnew and John von Neumann as a Committee on the Award of the Bôcher Prize, to be awarded at the 1948 Annual Meeting for the period 1943-1947; Drs. R. P. Boas (Chairman), Arthur Erdélyi, Professors George Pólya and Antoni Zygmund as a Committee on Known Results; Professors W. T. Martin (Chairman), T. R. Hollcroft, J. A. Stratton, and J. L. Synge as a Committee on Arrangements for the Second Annual Symposium in Applied Mathematics, to be held at Massachusetts Institute of Technology in 1948; Professors H. P. Evans 
(Chairman), R. H. Bruck, R. V. Churchill, Dr. B. H. Colvin, Professor H. M. Gehman, Dr. Elizabeth S. Sokolnikoff, and Professor R. D. Specht as a Committee on Arrangements for the 1948 Summer Meeting, to be held at the University of Wisconsin; Dr. E. R. Kolchin, Professors R. J. Levit and Walter Strodt as tellers for the 1947 election of officers and members of the Council; Professor T. H. Hildebrandt as a member of the Committee to Select Hour Speakers for Summer and Annual Meetings for the period 1948-1949 (committee now consists of Professors J. R. Kline, Chairman, T. H. Hildebrandt, and Oscar Zariski); Professor Deane Montgomery as a member of the Committee to Select Hour Speakers for Eastern Sectional Meetings for the period 1948-1949 (committee now consists of Professors T. R. Hollcroft, Chairman, W. T. Martin, and Deane Montgomery); Professor Marshall Hall as a member of the Committee to Select Hour Speakers for Western Sectional Meetings for the period 1948-1949 and Professor C. J. Nesbitt as a member of the same committee for the year 1948 (committee now consists of Professors R. H. Bruck, Chairman, Marshall Hall, and C. J. Nesbitt); Professor Ralph Hull as a member of the Committee to Select Hour Speakers for Far Western Sectional Meetings for the period 1948-1949 (committee now consists of Professors J. W. Green, Chairman, Ralph Hull, and C. B. Morrey); Professors J. C. Oxtoby and A. C. Schaeffer as members of the Committee on Publicity for the period 1948-1950 (committee now consists of Professors C. O. Oakley, Chairman, Garrett Birkhoff, J. C. Oxtoby, A. C. Schaeffer, R. M. Thrall, and R. J. Walker); Professor J. W. Tukey as a member and Chairman of the Committee on Reorganization of the Society's Programs; Professor J. W. T. Youngs as Acting Chairman of the Birkhoff Finance Committee, to serve until July 1, 1948; Professors S. B. Myers (Chairman), R. H. Bruck, Ben Dushnik,' J. S. Frame, T. H. Hildebrandt, and R. M. Thrall as a Committee on Arrangements for the April, 1948, meeting at the University of Michigan; Professors W. L. Ayres (Chairman), S. S. Cairns, B. P. Gill, J. R. Kline, P. A. Smith, and M. H. Stone as a Committee on Reorganization: Professor Hassler Whitney as Chairman of the Committee on Visiting Lectureships for the period 1948-1950 and Dean R. G. D. Richardson as a member of the same committee for the period 1948-1949 (committee now consists of Professor Hassler Whitney, Chairman, Dean R. G. D. Richardson, and Professor Norbert Wiener); Professor C. J. Rees as Chairman of the Committee on Printing Contracts for the period 1948-1950 (committee now consists of Professor C. J. Rees, Chairman, Dean M. H. Ingraham, and Professor J. M. Thomas); Professor 
G. B. Price as Chairman of the Committee on Places of Meetings for 1948 and Professor R. L. Wilder as a member of the committee for 1948-1950 (committee now consists of Professors G. B. Price, Chairman, C. B. Allendoerfer, and R. L. Wilder); Professors G. C. Evans (Chairman), J. R. Kline and G. T. Whyburn as a committee to nominate representatives of the Society on the Policy Committee for Mathematics; Dean Walter Bartky and Professor G. C. Evans as members of the Committee on Applied Mathematics for the period 1948-1950 (committee now consists of Professors J. L. Synge, Chairman, Walter Bartky, Richard Courant, G. C. Evans, John von Neumann, and William Prager); Professors D. V. Widder (Chairman), A. B. Coble, Arnold Dresden, T. H. Hildebrandt, and Deane Montgomery as a committee to nominate officers and committees for the International Congress of Mathematicians.

The following were reported as the Chairmen and voting members of Editorial Committees for the year 1948: Professor R. E. Langer, Bulletin; Professor A. A. Albert, Transactions; Professor A. W. Tucker, Mathematical Surveys; Professor J. F. Ritt, Colloquium.

It was reported that Professor G. A. Hedlund of the University of Virginia had accepted the invitation to deliver a series of Colloquium Lectures at the 1949 Summer Meeting.

The Secretary reported that the biennial membership campaign had been conducted during November, 1947, at which time 4,524 letters of invitation to join the Society were mailed to teachers of mathematics in the colleges and universities of the United States and Canada (including 515 invitations to members of the Association).

It was reported that a reciprocity agreement had been established between the Society and the Société Mathématique de France. The details of this agreement and of other reciprocity agreements are given elsewhere in this issue of the Bulletin.

At the annual election which closed on December 31, and at which 656 votes were cast, the following officers were elected:

Vice Presidents, Professors John von Neumann and Hassler Whitney.

Associate Secretaries, Professors R. H. Bruck, J. W. Green, and G. B. Price.

Librarian, Professor Arnold Dresden.

Members of the Editorial Committee of the Bulletin, Professor Nathan Jacobson and Dean E. B. Stouffer.

Member of the Editorial Committee of the Transactions, Professor G. T. Whyburn. 
Member of the Editorial Committee of the Colloquium Publications, Professor C. C. MacDuffee.

Member of the Editorial Committee of Mathematical Revierws, Professor William Feller.

Member of the Editorial Committee of Mathematical Surveys, Professor J. L. Walsh.

Representative on the Editorial Board of the American Journal of Mathematics, Professor Richard Brauer.

Members at large of the Council, Professors J. L. Doob, R. L. Jeffrey, J. B. Rosser, N. E. Steenrod, and Alfred Tarski.

The Secretary reported the resignation in November of Dr. Warren Weaver as a Trustee of the Society and the resignation, to be effective after January 17, 1948, of Professor G. W. Mullins as a Trustee. He further reported that Professor G. T. Whyburn had been elected by the Trustees to fill the unexpired term (to December 31, 1948) of Dr. Weaver.

The Librarian reported the following additions to the Library: 219 volumes of periodicals, 42 books, 82 pamphlets (including 72 dissertations). He also reported that exchanges with foreign periodicals are being reestablished and that he is assisting in the revival of mathematical activity abroad in so far as the policy of liberal exchange conditions can contribute to this end.

In an appendix to this report are excerpts from the report of the Treasurer for the fiscal year 1947 as verified by the auditors. A copy of the complete report will be sent, on request, to any member of the Society.

The American Journal of Mathematics reported that it had published 871 pages in 1947. The Society now contributes an annual subvention of $\$ 2,000$ to the American Journal.

Times and places for meetings of the Society in 1948 were set as follows: June 19 at the University of British Columbia; September 7-10 at the University of Wisconsin; October 30 in New York City; November 26-27 in Chicago, Illinois; November 27 at the University of California at Los Angeles. The Council voted in favor of holding regular meetings of the Society in the Pacific Northwest. On recommendation of the Committee on Places of Meetings, the Council voted to hold the 1948 Annual Meeting at The Ohio State University and the 1949 Annual Meeting in New York City, the latter to be held in conjunction with the meetings of the American Association for the Advancement of Science. (It has proved necessary to postpone the New York meeting from December, 1948, to December, 1949, because of the change in plans of the A.A.A.S.) 
Certain invitations to give addresses in 1948 were announced: Professor Eric Reissner for the February meeting in New York City; Professor André Weil for the February meeting in Chicago; Professors Charles Loewner and O. E. Neugebauer for the April meeting in New York; Professors Irving Kaplansky and H. S. M. Coxeter for the April meeting in Ann Arbor; Professor H. F. Bohnenblust for the April meeting in Berkeley; Professor J. W. T. Youngs for the Summer Meeting at the University of Wisconsin; Professor Mark Kac for the Annual Meeting at The Ohio State University.

Associate Secretary G. B. Price reported on the Society's plan for institutional contributing memberships. At the present time the Society has one hundred seven institutional contributing members which contribute over $\$ 9,000$ annually to the Society's publication program. Dues for institutional contributing members are computed every six years and are based on the number of pages published by the member's staff. The per page rate used at present is $\$ 2.75$; this rate has been used since institutional memberships were inaugurated in 1934 and does not reflect present printing costs. Professor Price pointed out that the Society's income from industry is very small and that the Society might well hope for an increase in income from this source, since an increasingly large number of persons employed by industry are becoming affiliated with the Society.

The Bulletin Editorial Committee reported that the high standard of acceptability for articles is being maintained, that the number of papers received from abroad has increased and that the flow of papers from this country has continued. Professors A. H. Clifford, M. M. Day, F. G. Dressel and G. W. Whitehead were reported as new Assistant Editors for the Bulletin.

The Transactions Editorial Committee reported that a total of 1,100 pages have been published in the 1947 volumes and that a backlog of papers accepted for publication is accumulating, so that a year will elapse between submission of a manuscript and publication. Professors Samuel Eilenberg and Harry Levy were reported as new Associated Editors and Professor A. A. Albert as Managing Editor for the year 1948.

The Mathematical Reviews Editorial Committee reported an increase in the amount of material to be reviewed, due to the availability of foreign journals and to the increased production in most countries. During 1947 the Matematisk Forening i Kobenhavn and the Polish Mathematical Society were added to the list of sponsors of Mathematical Reviews. The subscription list, as of December 1, 1947, was 1,765. A contract with the Office of Naval Research has recently 
been negotiated which will yield over $\$ 23,000$ during 1948 for the support of Mathematical Reviews.

On recommendation of the Colloquium Editorial Committee, the Council voted to recommend to the Trustees the acceptance of a revised edition of Lattice theory by Professor Garrett Birkhoff for publication in the Colloquium Series. On recommendation of the Mathematical Surveys Editorial Committee, a manuscript by Dr. Stefan Bergman entitled Methods in complex orthogonal functions was accepted for publication, subject to the approval of the Trustees.

It was reported that an Editorial Committee had started work on the compilation of material to be published as the Collected mathematical papers of G. D. Birkhoff and that the Finance Committee for the project had secured, as of December 12,1947, a total of $\$ 7,102.80$ in contributions and subscriptions.

The Council approved July 29-31, 1948, as the dates for the Second Symposium on Applied Mathematics, to be held at the Massachusetts Institute of Technology on the subject of Electro-magnetic theory. The Council also approved the recommendation that the following groups be invited to act as co-sponsors of the Symposium: American Institute of Physics, American Institute of Radio Engineers, American Institute of Electrical Engineers.

The Committee on Aid to Devastated Libraries reported that a second shipment of books and journals is on its way to twenty-four different libraries in ten different countries and that the committee hopes to find a satisfactory way for forwarding other material now at its disposal.

The Council voted to donate to the new journal, Applied Mechanics Reviews, two subscriptions to the Bulletin and Transactions.

The President was authorized to appoint a committee to consider the question of holding regular meetings of the Society in the southeastern section of the country. This action was taken at the request of a group of members of the Society representing various institutions in the southeast.

Abstracts of the papers read follow below. Papers whose abstract numbers are followed by the letter " $t$ " were read by title. Paper number 110 was presented by Dr. Cohen, number 122 by Professor Gustin, number 129 by Professor Cohen, number 149 by Dr. Neményi, number 169 by Professor Gottschalk, and number 176 by Professor Young. Dr. Dvoretzky was introduced by Professor Szolem Mandelbrojt and Professor Jacob Wolfowitz, Dr. Hu by Professor Oscar Zariski, and Mr. Seth by Professor Jacob Wolfowitz. 


\section{Algebra AND Theory OF Numbers}

106t. Grace E. Bates and F. L. Kiokemeister: An example in the theory of quasigroups.

A loop is constructed in such a way that its image under a given homomorphism is not a quasigroup. The loop may be commutative. It is shown that if under a given homomorphism of a loop the kernel is finite or the image is finite or the image is associative, then the image is a loop. (Received November 12,1947.)

\section{7t. Garrett Birkhoff and Orrin Frink: Representations of lattices by sets.}

This deals with methods of representing a general lattice $L$ by sets. The first part concerns lattices of subalgebras of abstract algebras. Necessary and sufficient conditions are given for $L$ to be isomorphic with the lattice of all subalgebras of a suitable abstract algebra. In a lattice satisfying these conditions, it is shown that every element is a meet of completely meet-irreducible elements. This generalizes the main result of Garrett Birkhoff on subdirect unions in universal algebra. Necessary and sufficient conditions are given for $L$ to be isomorphic with the lattice of all ideals of another lattice $A$. The second part deals with representations by sets of dual ideals. It is shown that isomorphic meet-representations are furnished by the use of all meet-irreducible, of all completely meet-irreducible, and of all principal dual ideals. In distributive lattices, meet-irreducible and prime dual ideals are shown to be the same. They provide the representation by Stone; while the more economical representation by sets of completely meet-irreducible dual ideals is equivalent to one given previously by Garrett Birkhoff. It is shown that in lattices with the disjunction property of Wallman, the representation by sets of maximal dual ideals is in general more economical still. In lattices with the descending chain condition, some of the representations considered reduce to that introduced by A. D. Campbell. (Received October 22, 1947.)

\section{8t. Bailey Brown and N. H. McCoy: The radical of a ring.}

In a previous paper (Amer. J. Math. vol. 69 (1947) pp. 46-58), a radical $N$ has been defined for an arbitrary ring $R$, and various theorems on the radical established by use of Zorn's Lemma. Certain of these theorems basic in the theory, for example, that $N$ is a two-sided ideal in $R$ and that $R / N$ has zero radical, are now proved by finite methods, as are also the following new results. The radical $N$ consists of the elements $b$ of $R$ such that the ideal $R b R$ is $H_{1}$-regular. If $A$ is a two-sided ideal in $R$, the radical of the ring $A$ is the intersection of $A$ and $N$. (Received November 18,1947.)

\section{9t. Leonard Carlitz: A problem of Dickson's.}

Let the homogeneous polynomial $Q(x, y)$ with coefficients in $G F\left(p^{n}\right)$, $p$.odd, be such that $Q(a, b)$ is a nonzero square in $G F\left(p^{n}\right)$ for all $(a, b)$ except $(0,0)$ in the field. Dickson (Trans. Amer. Math. Soc. vol. 10 (1909) pp. 109-122) calls such forms definite. He conjectured that every definite binary form of degree $2 r, r>1$, is the square of a polynomial with coefficients in $G F\left(p^{n}\right)$ provided $p^{n}$ exceeds a certain bound $N_{r}$; he proved this in the case $r=2,3$. In the present paper this conjecture is shown to be correct in the slightly more general case of polynomials $F(x)$ all of whose values are nonzero squares in $G F\left(p^{n}\right)$ : If $p^{n}>(k-1)^{2}$, where $k=\operatorname{deg} F$, then $F$ is a square. 
This follows easily from the Riemann hypothesis for the Artin zeta-function; the truth of this hypothesis has been proved by A. Weil (Proc. Nat. Acad. Sci. U.S.A. vol. 27 (1941) pp. 345-347). (Received October 16, 1947.)

\section{Leonard Carlitz and Eckford Cohen: Representations of $a$} polynomial in $G F\left[p^{n}, x\right]$ in certain special quadratic forms.

The authors are concerned with the number of representations of a polynomial in $G F\left[p^{n}, x\right]$ in the form $\sum \alpha_{i} X_{i}^{2}+\sum L_{i j} Y_{i} Y_{j}$, where $\alpha_{i} \in G F\left(p^{n}\right)$ and $\operatorname{deg} L_{i j} \leqq 1$. The method is an application of the singular series method developed in a recent paper (Duke Math. J. vol. 14 (1947)). (Received October 16, 1947.)

\section{1t. M. J. Herzberger and Robert Morris: Normal equations with} nearly vanishing determinants.

In least square problems it is frequently necessary to compute the coefficients of the normal equations with greater accuracy than the solution requires because of the fact that the determinant has fewer significant figures than the coefficients. In some cases, in which the number of digits is limited by the use of a calculating machine, a direct result is unobtainable. In the case of a small determinant, an approximate solution of the problem may be found, which is not an approximation to the exact solution of the normal equations but may have more significance than the exact solution, because of the fact that the data might be slightly in error. The paper shows how to obtain such approximations, using only a limited number of digits. By translating the algebraic problem into a problem of geometry, some help is given to the intuition of the computer in arranging the successive operations in the most effective order. (Received November 24, 1947.)

\section{2t. Saunders MacLane: $A$ non-associative method for associative} algebras.

In a forthcoming issue of Trans. Amer. Math. Soc. Ellenberg and the author have established the following theorem for a crossed product algebra $A$. Let $K \supset N \supset P$ be fields, $K$ and $N$ finite, normal and separable over $P$, and let $\sigma, \tau$ be automorphisms of $K / N, \alpha, \beta, \gamma$ automorphisms of $K$ over $P$. Let $f(\sigma, \tau)$ be a factor set in $K$ for the crossed product algebra $A=(K, f)$, and $h(\alpha, \beta)$ any extension of the function $f$ to all $\alpha, \beta$. If $h$ can be so chosen that $[\alpha \cdot h(\beta, \gamma)] h(\alpha \beta, \gamma)^{-1} h(\alpha, \beta \gamma) h(\alpha, \beta)^{-1}$ is a function $t\left(\alpha^{\prime}, \beta^{\prime}, \gamma^{\prime}\right)$ only of the automorphisms $\alpha^{\prime}, \beta^{\prime}, \gamma^{\prime}$ induced on $N$ by $\alpha, \beta, \gamma$, respectively, then every automorphism of $N / P$ can be extended to an automorphism of $A$, and $t$ is the "Teichmuller cocycle" of $A$. In the present paper the author gives a simple nonassociative proof of this theorem. (Received November 7, 1947.)

113t. G. D. Mostow: On closed subgroups of a Lie group. Preliminary report.

It is proved that a semi-simple Lie subgroup $S$ of a simply connected Lie group $G$ is closed in $G$. If $G$ is not simply connected, $S$ need not be closed. A corollary of this theorem is that there is no proper representation of a noncompact connected simple Lie group into a compact Lie group. (Received November 6, 1947.)

\section{4t. Gordon Pall: Composition of binary quadratic forms.}


A compound of binary quadratic forms is defined, and the uniqueness of the product class is proved, without the use of bilinear transformations. There is included also an extension to forms in $n$ variables of a criterion due to Gauss for the equivalence of binary quadratic forms. (Received November 24, 1947.)

\section{W. V. Parker: Characteristic roots and the field of values of $a$ matrix.}

Let $A=\left(a_{i j}\right)$ be an $n$-rowed square matrix of complex numbers and write $P_{k}$ $=\sum_{j=1}^{n}\left|a_{k j}\right|(j \neq k), \quad Q_{k}=\sum_{i=1}^{n}\left|a_{i k}\right|(i \neq k), \quad R_{k}=P_{k}+\left|a_{k k}-m\right|, \quad T_{k}=Q_{k}+\left|a_{k k}-m\right|$, where $m=n^{-1} \sum_{i=1}^{n} a_{i i}, 2 S_{k}=R_{k}+T_{k}$ and denote by $P, Q, R, S$ and $T$ the greatest of the $P_{k}, Q_{k}, R_{k}, S_{k}$ and $T_{k}$ respectively. In this paper it is shown that: 1 . The field of values of $A$ (the set of complex numbers $x A \bar{x}^{\prime}$ where $x \bar{x}^{\prime}=\sum_{i=1}^{n} x_{i} \bar{x}_{i}=1$ ) lies in the circle of radius $S$ with center at $m$. 2. Each characteristic root, $\lambda$, of the matrix $A$ lies in (or on) at least one of the $n$ ellipses $|\lambda-m|+\left|\lambda-a_{k k}\right|=P_{k}+R_{k}$ and in (or on) at least one of the $n$ ellipses $|\lambda-m|+\left|\lambda-a_{k k}\right|=Q_{k}+T_{k}$. 3. Each characteristic root, $\lambda$, of the matrix $A$ lies in (or on) at least one of the $n$ Cassini ovals $\left|\lambda-a_{k k}\right| \cdot|\lambda-m|$ $=P_{k} R_{k}$ and in (or on) at least one of the $n$ Cassini ovals $\left|\lambda-a_{k k}\right| \cdot|\lambda-m|=Q_{k} T_{k}$. (Received November 10, 1947.)

\section{6t. Edward Rosenthall: Multiplicative diophantine equations in quaternions.}

The diophantine equation $X Y=Z W$ in Lipschitz integral quaternions with proper parts of odd norm is solved completely in integral parameters, namely: $X=a b S \bar{S} F P A B C, \quad Y=c d T \bar{T} \bar{C} \bar{B} \bar{A}(\bar{P} K+\bar{L} M) E, \quad Z=a d C \bar{C} F(K \bar{M}+P \bar{L}) R S T, \quad W$ $=c b B \bar{B} \bar{T} S \bar{R} M E$, where the small letters represent rational integers and the others represent odd integral quaternions except that $K$ or $L$ must be even, and also $A \bar{A}$ $=R \bar{R}, P \bar{P}=M \bar{M}$, which can be solved explicitly in rational integral parameters (E. T. Bell, Trans. Amer. Math. Soc. vol. 57 (1945) p. 95). Through properties of these quaternions developed by G. Pall (Trans. Amer. Math. Soc. vol. 47 (1940) pp. 487-500) the resolution of this equation is made to depend on the system $P N=Q M$, $P \bar{P}=M \bar{M}$, the complete solution for which is $N=\bar{P} K+\bar{L} M, Q=K \bar{M}+P \bar{L}$. Other multiplicative equations are considered. (Received November 18, 1947.)

\section{7t. R. D. Schafer: Structure of genetic algebras.}

Etherington (in Proc. Roy. Soc. Edinburgh vol. 59 (1939) pp. 242-258, and other papers) has studied the non-associative algebras which arise in the symbolism of genetics. The author introduces a concept of genetic algebra which is intermediate between his (commutative) train algebra and special train algebra: a commutative baric algebra $A$ over $F$ is a genetic algebra in case the coefficients of the characteristic function $|\lambda I-T|$ of $T=\alpha I+f\left(R_{x_{1}}, R_{x_{2}}, \cdots\right)$ in the transformation algebra $T(A)$ are polynomials which, insofar as they depend on the $x_{i}$, depend only on the weights of the $x_{i}$. This definition is more satisfactory than that of special train algebra on two counts: the structure of the algebra is not postulated, and the duplicate of a genetic algebra is itself a genetic algebra (so that all of the fundamental algebras of symmetrical inheritance-zygotic, copular, and so on, as well as gametic-are genetic algebras). It is proved that the radical of $A$ is the kernel of the weight function, and that it is nilpotent. Some special cases are treated in detail. (Received November 25, 1947.) 


\section{8t. A. R. Schweitzer: Remarks on fields of ordered dyads.}

Postulates are constructed for a field of ordered dyads which permit interpretation of the latter as rational numbers. The postulates are based on multiplicative and additive groups of dyads and are analogous to postulates for a field previously reported (Bull. Amer. Math. Soc. Abstract 52-11-353). The postulates for the multiplicative group are the same as those given in the author's paper, Remarks on groups of ordered dyads (Bull. Amer. Math. Soc. Abstract 54-1-11). The postulates for the additive group are first stated in terms of undefined addition of dyads with the same posterior elements; it is then assumed: $1 . \alpha / \beta, \gamma / \delta$ in $T$ imply the existence of $\xi, \eta, \zeta$ in $S$ such that $\alpha / \beta=\xi / \zeta, \gamma / \delta=\eta / \zeta ; \alpha / \beta, \gamma / \delta, \lambda / \mu$ in $T$ imply the existence of $\xi, \eta, \zeta, \tau$ in $S$ such that $\alpha / \beta=\xi / \tau, \gamma / \delta=\eta / \tau, \lambda / \mu=\zeta / \tau .2 . \xi / \tau+\eta / \tau=\zeta / \tau, \xi^{\prime} / \tau+\eta^{\prime} / \tau=\zeta^{\prime} / \tau, \xi / \tau$ $=\xi^{\prime} / \tau, \eta / \tau=\eta^{\prime} / \tau$ imply $\zeta / \tau=\zeta^{\prime} / \tau$. Definition. $\alpha / \beta+\gamma / \delta=\lambda / \mu$ means: There exist $\xi, \eta, \zeta, \tau$ in $S$ such that $\alpha / \beta=\xi / \tau, \gamma / \delta=\eta / \tau, \lambda / \mu=\zeta / \tau, \xi / \tau+\eta / \tau=\zeta / \tau$. (Received November 24, 1947.)

\section{9t. Olga Taussky and John Todd: Covering theorems for groups.}

The following two problems have been studied. (1) $G$ being an abelian group with $n$ generators each of order $p, S$ being the set of the $s=n(p-1)+1$ distinct powers of each of the elements of a fixed base, determine the smallest integer $\sigma$ for which there exists at lest one set $\Sigma$ of $\sigma$ elements of $G$ such that $G=\Sigma S$. (2) Determine the cases when $\Sigma$ can be a subgroup or a coset in $G$ as in the cases $p=2, n=7 ; p=3, n=4$. (Received October 31, 1947.)

\section{ANALysis}

\section{R. P. Agnew: Abel transforms and partial sums of Tauberian} series.

Let $u_{0}+u_{1}+\cdots$ be a series of complex terms for which $L=\lim$ sup $\left|n u_{n}\right|<\infty$. Let $\sigma(t)=\sum t^{k} u_{k}(0<t<1)$ and let $s(x)=u_{0}+u_{1}+\cdots+s_{n}$ where $n$ is the greatest integer not greater than $x$. Let $q>0$. Then, as $t \rightarrow 1-$, the relation $\left(^{*}\right) \lim \sup \mid \sigma(t)$ $-s\left(q / \log t^{-1}\right) \mid \leqq A(q) L$ holds when $A(q)$ is the constant defined by $A(q)=\gamma+\log q$ $+2 \int_{q}^{\infty} x^{-1} e^{-x} d x$. Moreover $A(q)$ is the best constant in the following sense. There is a real series $\sum u_{n}$ such that $0<L<\infty$ and the members of $\left({ }^{*}\right)$ are equal. The same is true when the relation $\left({ }^{*}\right)$ is replaced by the relation $\left(^{* *}\right) \lim \sup _{n \rightarrow \infty}\left|\sigma\left(e^{-q / n}\right)-s(n)\right|$ $\leqq A(q) L$. This generalizes and unifies special results obtained in six recent papers by Hadwiger, Agnew, Hadwiger, Wintner, Hartman, and Hadwiger for special cases in which $q=\log 2$ and $q=1$. Relations among the six papers are set forth in recent and forthcoming issues of Mathematical Reviews. (Received November 17, 1947.)

121. D. F. Barrow: On expressing a function of three variables in nomograph form.

A function of three variables $(x, y, z)$ is in nomograph form if it is expressed as a three-rowed determinant whose first, second, and third rows are functions of $x$ alone, of $y$ alone, and of $z$ alone respectively. Nine necessary and sufficient conditions that a given function may be so expressed are found. These conditions are in the form of determinants which must vanish identically, the elements of the determinants being the given function and certain of its derivatives. Also, a formula is furnished for expressing the function in nomograph form if this is possible. (Received October 24, 1947.) 
122. E. F. Beckenbach and William Gustin: On the mean modulus of an analytic function.

Let $f$ denote a function of a complex variable analytic in the open unit circle. In this paper the convexity properties of the circumferential and areal mean moduli of order $t(0 \leqq t \leqq \infty)$ of the analytic function $f$ over a circle of radius $r(0 \leqq r<1)$ are investigated as functions of $r$. It is known that the logarithm of such a mean modulus is a convex function of $\log r$ for any $f$ and any $t$; for $t=\infty$ this is the Hadamard three circle theorem. The following results are obtained. The set of $t$-values for which the circumferential mean modulus is a convex function of $r$ for any $f$ is a closed bounded set which includes the $t$-values $0,1 / 2,2 / 3,1,2$; and the set of $t$-values for which the areal mean modulus is a convex function of $r$ for any $f$ is a closed bounded set which includes the $t$-values $0,1,2$. (Received November 10,1947.)

\section{3t. Stefan Bergman and M. M. Schiffer: Kernel functions in the theory of partial differential equations of elliptic type.}

Let $B$ be a plane domain with smooth boundary $C . P(Z)$ is a continuous positive function of $Z \equiv(x, y)$ in $B$. Let $a(Z)$ and $b(z)$ be continuous differentiable in $B$ and in $C$ and suppose $a(Z) \cos (n, x)+b(Z) \cos (n, y)=-\lambda(Z)$ on $C$ continuous and negative. The scalar product $D(\phi, \psi)=\iint_{B}\left[\phi_{x} \psi_{x}+\phi_{y} \psi_{y}+(a \phi \psi)_{x}+(b \phi \psi)_{y}+P \phi \psi\right] d x d y$, $\phi_{x}=\partial \phi / \partial x, \cdots$, is defined for each pair $\phi, \psi$ in the function space $\Omega$, consisting of all continuously differentiable functions in $B$ for which $D\{\phi, \phi\}<\infty$, the integrals understood in the Lebesgue sense. In the subspace $\Lambda$ of $\Omega$, consisting of all solutions of $\Delta \phi=P \phi$, choose a complete system $\left\{\phi_{\nu}(Z)\right\}$ orthonormalized with respect to the $D$ metric. Its kernel function $K(Z, W)=\sum_{\nu=1}^{\infty} \phi_{\nu}(Z) \phi_{\nu}(W)$ satisfies $K(Z, W)=R(Z, W)$ $-G(Z, W) ; G(Z, W)$ is Green's function of the differential equation and $R(Z, W)$ the fundamental solution satisfying on $C: \partial R / \partial n=\lambda R$. In the case $\lambda=a=b=0, R(Z, W)$ equals the Neumann function (cf. Bergman-Schiffer, Duke Math. J. vol. 14 (1947) pp. 609-638). The kernel function is always non-negative in $B$ and satisfies $K(Z, W)^{2}$ $\leqq K(Z, Z) K(W, W)$. If $R_{\nu}(Z, W)$ satisfies $\partial R_{\nu} / \partial n=\lambda_{\nu} R_{\nu}$ on $C(\nu=1,2)$ and if $\lambda_{1}>\lambda_{2}$ one has $R_{2}(Z, W) \geqq R_{1}(Z, W)$ in $B$. (Received December 22, 1947.)

124t. Stefan Bergman and M. M. Schiffer: On nonlinear differential equations of elliptic type.

We use the notations of the preceding abstract. Let $P_{1}(Z)>P_{2}(Z)>0$ be two continuous functions in $B$. Consider the two differential equations $\Delta \phi=P_{\nu} \phi(\nu=1,2)$. For a fixed continuous function $\lambda(Z)>0$ on $C$ we have two corresponding fundamental solutions $R_{\nu}(Z, W)$. There holds: $R_{1}(Z, W)<R_{2}(Z, W)$ in $B$. The same inequality holds for the corresponding Green's functions and kernel functions. Using these facts, the following theorem is proved: Let $P\left(Z ; t, t^{\prime}, t^{\prime \prime}\right)$ be defined for $Z \in B$ and real $t, t^{\prime}, t^{\prime \prime} ;$ suppose that a Lipschitz condition $\left|P\left(Z ; t, t^{\prime}, t^{\prime \prime}\right)-P\left(Z ; t_{1}, t_{1}^{\prime}, t_{1}^{\prime \prime}\right)\right|<K$ $\cdot \max \left\{\left|t-t_{1}\right|,\left|t^{\prime}-t_{1}^{\prime}\right|,\left|t^{\prime \prime}-t_{1}^{\prime \prime}\right|\right\}$ and the inequality $M \geqq P\left(Z ; t, t^{\prime}, t^{\prime \prime}\right) \geqq m>0$ hold. Then the differential equation $\Delta \phi=P(Z ; \phi, \partial \phi / \partial x, \partial \phi / \partial y) \cdot \phi$ possesses always solutions for continuously prescribed boundary values on $C$. Generalizations of this theorem in various directions are indicated. (Received December 22, 1947.)

\section{L. M. Blumenthal: Metric methods in linear inequalities.}

Irreducible systems of linear inequalities in $n+1$ indeterminates $(n \geqq 1)$, of arbitrary power not greater than $c$, are studied by applying metric-theoretic methods and 
results to the subset $C$ of the unit $n$-sphere $S_{n, 1}$ formed by normalizing the coefficient set, and the closed, convex subset $\Sigma(C)$ of $S_{n, 1}$ whose elements correspond to the normalized solutions of the system. Among properties established for the set function $\Sigma$ are: (1) $\Sigma(C)=\Sigma(\bar{C})=\Sigma\left(C^{*}\right)$, where $\bar{C}, C^{*}$ denote closure and convex extension of $C$, respectively; (2) $\Sigma(C)=C$ provided $C$ is closed, convex, and $p \in B(C)$, the boundary of $C$, implies $\operatorname{diam}_{p} B(C)=\pi / 2 ;(3) \Sigma(C)=C$ implies $B(C)$ of constant (spherical) breadth, but not conversely; (4) $\Sigma^{3}(C) \equiv \Sigma(\Sigma(\Sigma(C)))=\Sigma(C)$ for every $C$. New criteria for existence of solutions (and geometric derivations of some previously known) are given. A chain of existence theorems is obtained by proving that a system of inequalities, in the wide sense, has a nontrivial solution if and only if each $n+k+1$ of them has a nontrivial solution in common with an arbitrarily selected subsystem of $n-k+1$ inequalities whose representative points of $S_{n, 1}$ do not lie on an $S_{n-k-1,1}$, where $k$ may be any one of the numbers $0,1, \cdots, n+1$. (Received November 19, 1947.)

\section{6t. Robert Breusch: On the distribution of the values of $|f(z)|$ in the unit circle.}

Let $f(z)=\prod_{\nu=1}^{n}\left(z-z_{\nu}\right)$ be a polynomial with $\prod_{\nu=1}^{n}\left|z_{\nu}\right|=1$. If $A(f)$ is the area of the region of the unit circle where $|f(z)| \geqq 1$, then obviously $0 \leqq A(f) \leqq \pi$. It is shown that this estimate cannot be improved. That is, if $\alpha$ and $\beta$ are two non-negative real constants such that $\alpha \leqq A(f) \leqq \pi-\beta$ for every $f(z)$, then $\alpha=\beta=0$. That $\beta=0$ is trivial; for example consider $f(z)=1+N \cdot z+z^{2}$, with large $N$. To prove that $\alpha=0$, it is shown that to every polynomial $f(z)$ another polynomial $f_{1}(z)$ may be constructed such that $A\left(f_{1}\right)<2 A(f) / 3$. (Received November 21, 1947.)

\section{7t. K. Chandrasekharan. On Fourier series in several variables.}

If $f_{p}(t)$ is the spherical mean of order $p$ of the function $f\left(x_{1}, \cdots, x_{k}\right)$ at a given point, and $S^{\delta}(R)$ is the Riesz mean of order $\delta$ of the multiple Fourier series of $f\left(x_{1}, \cdots, x_{k}\right)$ at that point (Proc. Indian Acad. Sci. vol. 24 (1946) pp. 229-232), a formula is established, which expresses $f_{p}(t)$ as a transform of $S^{\delta}(R)$ for almost all $t$, and for $p>\delta-(k-1) / 2$. As consequences of the formula, theorems are obtained which affirm the existence of the mean limit of a function on condition that its Fourier series be summable. Some of the results seem to be new even in the case of functions of a single variable. (Received November 10,1947.)

\section{F. E. Clark: Positive representation of forms.}

Let $F$ be a form with real coefficients and degree $p$ in the variables $x_{1}, \cdots, x_{m}$, which range independently over all non-negative values except $0, \cdots, 0$. It is known that the form $F$ is positive if and only if there exists a form $f$ such that $f$ and $f F$ have positive coefficients. For $m=p=2$, Meissner (Über positive Darstellungen von Polynomen, Math. Ann. vol. 70 (1911) pp. 223-235) gave a system of inequalities on the coefficients of $f$, found the minimum $n$ ( $=\operatorname{deg} f$ ) for which that system is consistent, and solved the system in terms of an integral. His method was geometric throughout. In the present paper the author solves this system by means of a finite sum. P6lya has proved the general result, using an $f$ with multinomial coefficients but giving no information about the value of $n$. For the case of multinomial coefficients and $m=p=2$, the author gives a formula for the minimum $n$, which is shown to be odd and in general much larger than that for the Meissner problem. (Received November 21, 1947.) 
129. L. W. Cohen and Casper Goffman: $A$ theory of transfinite convergence.

A theory of convergence based on the definition of a sequence as a function $x \xi$ on the domain of ordinals $\xi<\xi^{*}$ to a uniform space is given. It yields the category theorem for complete spaces and covering theorems of Lindelöf and Borel-Lebesgue in which $\aleph_{0}$ is replaced by the cardinal of $\xi^{*}$. The ordinal $\xi^{*}$ is required to be the initial ordinal of its cardinal $\Xi^{*}$ and have the property that if $\eta^{*}<\xi^{*}$ and $\xi_{\eta}$ is single-valued on $\eta<\eta^{*}$ to $\xi<\xi^{*}$ then sup $\left[\xi_{\eta} \mid \eta<\eta^{*}\right]$. Examples are $\omega$, the classical case, and $\Omega$. The uniform space is a set $S=[x]$ with neighborhoods $U_{\xi}(x), \xi<\xi^{*}$, having the following properties: (1) $\bigcap_{\xi<\xi^{*}} U_{\xi}(x)=x$, (2) $U_{\xi}(x)$ decreases on $\xi<\xi^{*}$, (3) if $\eta<\xi^{*}$ there is a $\xi(\eta)$ such that $U_{\xi(\eta)}(y) \bigcap U_{\xi(\eta)}(x) \neq 0$ implies $U_{\xi(\eta)}(y) \subset U_{\eta}(x),(4)$ if $U_{\xi_{\eta}}\left(x_{\eta}\right)$ decreases on $\eta<\eta^{*}<\xi^{*}$ then $\bigcap_{\eta<\eta^{*}} U_{\xi_{\eta}}\left(x_{\eta}\right)$ is a nonempty open set. Examples are given and it is shown that if (4) is replaced by $\left(4^{\prime}\right)$ in which $x_{\eta}=x$ for $\eta<\eta^{*}$ then there are spaces with $\xi^{*}>\omega$ which are $\xi^{*}$-complete and of the first $\xi^{*}$-category. (Received November 24, 1947.)

\section{Aryeh Dvoretzky: On sections of power series.}

Through the use of the theory of normal families many extensions of the theorem of Jentzsch are obtained. The following results are typical. (1) Let $f(z)=\sum_{0}^{\infty} a_{n} z^{n}$ have 1 as radius of convergence, let $\left\{\rho_{n}\right\}$ be a sequence of positive numbers satisfying (*) $\log \rho_{n}=o(n)$, let $z_{0}$ be any number with $\left|z_{0}\right|=1$ and $\epsilon>0$ arbitrarily small. Then there exist infinitely many $n$ for which $w=s_{n}(z)=\sum_{1}^{n} a_{\nu} z^{\nu}$ maps $\left|z-z_{0}\right|<\epsilon$ on a domain completely covering $|w|<\rho_{n}$. (2) Let $m=m(n)$ be $o(n)$; then under the same conditions as in (1) there exist infinitely many $n$ for which $w=\sum_{m}^{n} a_{\nu} z^{\nu}$ maps $\left|z-z_{0}\right|<\epsilon$ on a domain completely covering $1 / \rho_{m}<|w|<\rho_{n}$. (3) If in addition to the assumptions made in (1), $z_{0}$ is a regular point of $f(z)$, then there exist infinitely many $n$ for which $w=f(z)-s_{n}(z)$ maps $\left|z-z_{0}\right|<\epsilon$ on a domain completely covering $1 / \rho_{n}<|w|<\rho_{n}$. It is easy to show that $\left(^{*}\right)$ cannot be essentially relaxed; the exclusion of the neighborhood of $w=0$ in (2) and (3) is also essential. Finally, a result of another nature may be mentioned. (4) Let $0<\lim \sup _{n-\infty}\left|a_{n}\right|<\infty$, let $z_{0}$ with $\left|z_{0}\right|=1$ be a regular point of $\sum_{0}^{\infty} a_{n} z^{n}$ and $d_{n}$ the distance from $z_{0}$ to the nearest root of $\sum_{0}^{n} a_{\nu} z^{\nu}=0$, then lim inf $n d_{n} / \log n<\infty$. (Received November 24, 1947.)

\section{Tomlinson Fort: The value of a product.}

In this paper the product $L_{w}=\left(1-L_{1 v}\right)\left(1-L_{2 w}\right) \cdots\left(1-L_{w v w}\right)$ and the infinite product, where $w$ becomes infinite, are considered. Both products are transformed into series; the finite product into the sum obtained by performing the indicated multiplication and the infinite product into the corresponding infinite series. Known relations among the elementary symmetric functions are used in studying the resulting series. Several theorems are proved. Formulae to facilitate the calculation of the first few terms of the series are developed. (Received November 3, 1947.)

\section{2t. Evelyn Frank: Orthogonality properties of $C$-fractions.}

Let the polynomials $B_{p}^{*}(z)=z^{n} B_{p}(1 / z)=\beta_{0}^{(p)} z^{n}+\beta_{1}^{(p)} z^{n-1}+\cdots+\beta_{n}^{(p)}, n=h_{p}=\alpha_{1}$ $+\alpha_{3}+\cdots+\alpha_{2 q-1}$, if $p=2 q-1$, or $n=g_{p}=\alpha_{2}+\alpha_{4}+\cdots+\alpha_{2 q}$, if $p=2 q$, be determined by the formulas $B_{0}^{*}(z)=1, \quad B_{1}^{*}(z)=z^{\alpha_{1}} B_{0}^{*}(z)=z^{\alpha_{1}} B_{1}(1 / z), \quad B_{2 p-1}^{*}(z)=z^{h} p_{p-1} B_{2 p-2}^{*}(z)$ $+a_{2 p-1} B_{2 p-3}^{*}(z)=z^{h} p B_{2 p-1}(1 / z), \quad B_{2 p}^{*}(z)=z^{0} p_{p} B_{2 p-1}^{*}(z)+a_{2 p} B_{2 p-2}^{*}(z)=z^{0} p B_{2 p}(1 / z)$. The $B_{p}(z)$ are the denominators of the approximants of an $\alpha$-regular $C$-fraction $C(z)$ (Frank, Amer. J. Math. vol. 68 (1946)). If $S$ is defined as the operator which replaces every 
$z^{p}$ by $c_{p+1}$ in any polynomial upon which it operates, then the orthogonality relations $S\left(B_{2 p}^{*} B_{2 k}^{*}\right)=0$ if $k \neq p, \omega=0, S\left(B_{2 p}^{*} B_{2 k}^{*}\right) \neq 0$ if $\omega \neq 0$, hold with respect to the $c_{p}$, and similar conditions are shown to hold for $S\left(B_{2 p}^{* 2}\right), S\left(B_{2 p-1}^{*} B_{2 k-1}^{*}\right), S\left(B_{2 p-1}^{* 2}\right), S\left(B_{2 p}^{*} B_{2 p-1}^{*}\right)$, $S\left(B_{2 p-2}^{*} B_{2 p-1}^{*}\right)$. Orthogonality relations are also shown for regular $C$-fractions (cf. Amer. J. Math. vol. 68 (1946) p. 94). If the even approximants of $C(1 / z)$ are regarded as generalizations of the approximants of a $J$-fraction (Bull. Amer. Math. Soc. vol. 52 (1946) pp. 144-157), the above orthogonality relations reduce to the known relations $S\left(B_{p} B_{q}\right)=0, p \neq q, S\left(B_{p} B_{q}\right) \neq 0, p=q$. (Received November 24, 1947.)

\section{3t. R. E. Fullerton. Integral distances in Banach spaces.}

Let $x_{n}$ be an infinite set of points in a Banach space $B$ such that $\left\|x_{i}-x_{j}\right\|$ is an integer for each $i$ and $j$. If $B$ is not strictly convex there exists such a set which does not lie on a line. If $B$ is strictly convex, no infinite subset lies on a line unless all the points of the set lie on the line. (Received November 24, 1947.)

\section{Casper Goffman: New proof of a theorem of Saks and Sier-} pinski.

A simple proof is given of the following theorem of Saks and Sierpinski: If $f(x)$ is an arbitrary real function on the closed interval $[0,1]$, there is a function $\phi(x)$ of Baire class 2 at most, such that for every $\epsilon>0,|\phi(x)-f(z)|<\epsilon$ on a set of exterior measure 1. The proof given rests on the following lemma which seems to be new. If $f(x)$ is an arbitrary real function on the closed interval $[0,1], \epsilon>0$, and $\phi(x)$ a continuous function such that $|\phi(x)-f(x)|<\epsilon$ on a set of exterior measure greater than $1-\epsilon$, then for every $\eta>0$, there is a continuous function $\psi(x)$ such that $|\psi(x)-\phi(x)|<\epsilon$ on a set of measure greater than $1-\epsilon$ and $|\psi(x)-f(x)|<\eta$ on a set of exterior measure greater than $1-\eta$. (Received November 24, 1947.)

\section{M. O. Gonzalez: On the solution of ordinary differential equa-} tions of the first order invariant under contact transformations.

In the classical Lie theory it is shown how to construct a differential equation invariant under a given group, and how to solve an equation when a group leaving the equation invariant is known. However, little is said about the problem of determining the group for a given differential equation, which is by far the most interesting problem. In the present paper, necessary and sufficient conditions for the existence of an infinitesimal contact transformation leaving a given equation invariant are determined along with the general form of the characteristic function of the group. It will also be shown how to reduce, by a proper change of variables, the infinitesimal contact transformation to a point transformation. This enables one to solve the transformed differential equation by Lie's methods. Passing back to the original variables, a new differential equation is obtained which combined with the original equation gives its solution in parametric form. (Received November 13,1947.)

136. H. L. Krall: On orthogonal polynomial solutions of certain differential equations of orders four and six.

Let $\rho(x)$ represent the weight functions of the classical orthogonal polynomials of Legendre, Jacobi and Laguerre: $1,(1-x)^{\alpha}(1+x)^{\beta}, e^{-x}$ respectively (in the Jacobi case assume $\alpha \beta=0$ ). The author studies the orthogonal polynomials having the Stieltjes 
weight function $\rho(x) d \psi(x)$, where $\psi(x)$ has a jump at the end or ends of the interval, and $\psi(x)=x$ in the interior. These polynomials satisfy a differential equation of the form $\sum_{i=0}^{r} \sum_{j=0}^{i} l_{i j} x^{j} y_{n}^{(i)}(x)=\lambda_{n} y_{n}(x)$ with $r=4$, and also with $r=6$. By elimination, differential equations of the second order are obtained for these polynomials. (Received November 14, 1947.)

\section{7t. Norman Levinson: $A$ simple second order differential equation} with singular motions.

Cartwright and Littlewood have announced the equation $\ddot{x}+k\left(x^{2}-1\right) \dot{x}+x$ $=b k \lambda \cos \lambda t$ has singular motions. Here a simple proof for singular motions is given for $\ddot{y}+p(y) \dot{y}+y=c \sin t$ where $p(y)$ is a polynomial and $c$ constant. In $\left(^{*}\right) \epsilon \ddot{x}+\phi(x) \dot{x}+\epsilon x$ $=b \sin t$ let $\epsilon>0$ be small and let $\phi(x)=1,|x|>1, \phi(x)=-1,|x|<1$. Clearly $\left(^{*}\right)$ can be solved explicitly. Certain families of solutions starting. at $t=\pi+\tau,|\tau-\epsilon / b| \leqq k \epsilon$ where $k$ is small, with $x=-1$ all eventually cross $x=1$ from above to below over a range in $t$ that includes $t=2 n \pi+\tau$ and $t=2(n+1) \pi+\tau$ where $|\tau-\epsilon / b| \leqq 2 k \epsilon$. Each of the $\tau$ intervals on $x=1$ then map into two others on $x=-1$, and so on. Therefore, there exists (Cartwright and Littlewood) a motion corresponding to any infinite array of $(2 n \pm 1) \pi$. Next let $\epsilon \dot{x}_{1}=x_{2}-\Phi\left(x_{1}\right), \dot{x}_{2}=-\epsilon x_{1}+b \sin t$ where $\Phi^{\prime}(x)=\phi(x)$. Here $x_{1}$ is $x\left(^{*}\right)$. Let $P(x)$ be a polynomial such that $P(x)-\Phi(x)$ is small for $|x|<6$. Then the solutions $\left(y_{1}, y_{2}\right)$ of $\epsilon \dot{y}_{1}=y_{2}-P\left(y_{1}\right), \dot{y}_{2}=-\epsilon y_{1}+b \sin t$ are near $\left(x_{1}, x_{2}\right)$. If $y=y_{1}$, this implies $(y, \dot{y})$ is near $(x, \dot{x})$ and therefore the same mapping of $\tau$ intervals holds for $y$ as for $x$ thereby giving singular motions for $y$ just as for $x$. (Received November 13, 1947.)

138. R. J. Levit: $A$ lower bound for the maximum absolute value of a real function on a finite set.

Let $S_{n}$ be a finite set of real numbers, $x_{0}<x_{1}<\cdots<x_{n}$, and $f(x)$ a function which is real and single-valued over $S_{n}$ and has the $n$th divided difference $f\left(x_{0}, \cdots, x_{n}\right)=f_{n}$. In this paper it is shown that the maximum absolute value of $f(x)$ over $S_{n}$ cannot be less than a certain number $M_{n}=M\left(f_{n} ; x_{0}, \cdots, x_{n}\right)$. Results of this kind for the case of $f(x)$ a polynomial have been obtained by G. Polya (Jber. Deutschen Math. Verein. vol. 28 (1919) pp. 31-40) and T. Tatuzawa (Proc. Imp. Acad. Tokyo vol. 15 (1939) pp. 253-254). A lower bound is found for the maximum absolute increment, $\mid f\left(x_{i}\right)$ $-f\left(x_{i}\right) \mid$, also. Both bounds are in a certain sense "best possible." If $f(x)$ has a finite derivative of order $n$, the foregoing results yield a generalization of the mean value theorem for derivatives. A geometric interpretation of the bound $M_{n}$ is given, and various applications of the theory are made. (Received November 24, 1947.)

139t. E. P. Miles: An integral formula for harmonic functions. Preliminary report.

Let $u \in L$ on the surface $\sigma$ of a sphere of radius $a$ about 0 . Let $U$ be the function, harmonic in the interior of $S$ of $\sigma$, given by the Poisson integral of u. Let $|\nabla U|$ be the magnitude of the gradient of $U$. The author proves that (1) $\iiint_{S}|\nabla U|^{2} \partial V=(1 / 4 \pi) \cdot \iint_{\sigma} \iint_{\sigma}[u(P)-u(Q)]^{2} d \sigma_{P} d \sigma_{Q} / \overline{P Q^{3}}=\sum_{n=1}^{\infty}(2 a n \pi / 2 n+1)\left\{2 A_{n}^{2}\right.$ $\left.+\sum_{m=1}^{n}[(n+m) ! /(n-m) !]\left(A_{n, m}^{2}+B_{n, m}^{2}\right)\right\}$, where $A_{n}, A_{n, m}$, and $B_{n, m}$ are coefficients in the Laplace series for $u$. The equalities (1) are analogues for three dimension of similar equalities for two dimensions obtained by J. Douglas in his paper Solution of the problem of Plateau, Trans. Amer. Math. Soc. vol. 33 (1931) pp. 263-321. (Received October 24, 1947.) 


\section{0t. Harold Shniad: On the convexity of mean value functions.}

Let a set of $n$ distinct positive numbers $a_{1}, a_{2}, \cdots, a_{n}(n \geqq 2)$ be given and labeled so that $a_{1}<a_{2}<\cdots<a_{n}$. Let $M_{t}(a, \xi)$ denote the mean value function $\left(\sum_{\nu=1}^{n} \xi_{\nu} a_{\nu}^{t}\right)^{1 / t}$, where $\left(\xi_{\nu}\right)$ is a set of $n$ fixed positive numbers with $\sum_{\nu=1}^{n} \xi_{\nu}=1$. The convexity and concavity of the functions $M_{t}(a, \xi)$ and $\Lambda(t)\left(=\log M_{t}(a, \xi)\right)$ are studied. If there exists a point $\bar{t}$ such that a function $g(t)$ defined on the range of reals is convex for $t<\bar{t}$ and concave for $t>\bar{t}$, we say that $g(t)$ is convex-concave. It is shown that there exists a point $t_{1}$ such that $\Lambda(t)$ [and therefore $M_{t}(a, \xi)$ ] is convex for $t<t_{1}$, that there exists a point $t_{2}$ such that $\Lambda(t)$ is concave for $t>t_{2}$, but that neither the function $\Lambda(t)$ nor the function $M_{t}(a, \xi)$ is necessarily convex-concave. If $\xi_{1} \geqq 1 / 2$, then $\Lambda(t)$ is convex for all negative $t$; and if $\xi_{n} \geqq 1 / 2$, then $\Lambda(t)$ is concave for all positive $t$. Finally it is shown that even if the condition $\sum_{v_{n-1}}^{*} \xi_{v}=1$ is removed, the zeros of the second derivative of $\Lambda(t)$ are bounded. (Received November 21, 1947.)

\section{Otto Szász: On Tauberian theorems for generalized Lambert} series and integrals.

Consider the integral transform $I_{\beta}(t)=\int_{0}^{\infty} p_{\beta}(t u) d A(u)$, where $p_{\beta}(x)=x^{\beta+1} \sum_{1}^{\infty} n^{\beta} e^{-n x}$, and $A(u)$ is such that $I_{\beta}(t)$ exists for $t>0$. If $A(u)$ is a step function with jumps $a_{n}$ at points $\lambda_{n}$, then the transform reduces to $L_{\beta}(t)=\sum a_{n} p_{\beta}\left(t \lambda_{n}\right)$. In particular for $\beta=0, p_{0}(x)=x e^{-x} /\left(1-e^{-x}\right), \alpha_{0}(t)=t \sum a_{n} \lambda_{n} e^{-\lambda_{n} t} /\left(1-e^{-\lambda_{n} t}\right)$. A Tauberian theorem for this transform, when the coefficients are positive, was given by V. Ganapathy Iyer on using the general Tauberian theorem of $\mathrm{N}$. Wiener. The author gives a Tauberian theorem for the transform $I_{\beta}(t)$, when $A(u)$ is monotone, by using the following theorem on closure: the sequence $p_{\beta}(n t) / p_{\beta}(t), n=1,2, \cdots,-1<\beta \leqq 2$, is closed in $C(0, \infty)$. He gives an elementary proof for this theorem with the aid of Möbius' inversion formula utilizing a remark due to J. Korevaar. In the generalization of a theorem of Hardy and Littlewood, however, transcendental methods are required. (Received November 15, 1947.)

142t. Olga Taussky: $A$ boundary value problem for a hyperbolic differential equation arising in the theory of the non-uniform supersonic motion of an aerofoil.

A solution of the linearized equation for the velocity potential of a non-uniform supersonic two-dimensional motion is obtained in terms of the normal derivative along the aerofoil. The problem is treated as a Cauchy problem since the values of the potential along the aerofoil can be eliminated by a reflexion. The expression coincides with a formula of C. Possio. The treatment is a generalization of a procedure used by G. Temple and H. A. Jahn in the case of harmonic motion. (Received November 15, 1947.)

\section{H. P. Thielman: On commutative functions and functional equations.}

Two functions $f(x)$ and $g(x)$ are said to be commutative if $f\{g(x)\}=g\{f(x)\}$. The functional product $f\{g(x)\}$ is designated by $f g(x)$, or simply by $f g$. The product of ordinary multiplication of $f(x)$ by $g(x)$ is indicated by $f(x) \cdot g(x)$. Use is made of the notation and certain methods and results of A. G. Walker's papers Commutative functions (Quarterly Journal of Mathematics vol. 17 (1946) pp. 65-92). A function $f(x)$ is said to be expressed in canonical form if $f(x)=\psi^{-1} \alpha \psi(x)$, where $\alpha$ is a constant and $\psi^{-1}$ is 
the inverse of $\psi(x)$. A number of theorems are proved on the equivalence of canonical forms. The functional equation $f[\phi(x, y)]=f(x) \cdot f(y)$ is considered with $\phi(x, y)$ $=\psi^{-1}[\psi(x)+\psi(y)]$. It is proved that all continuous solutions of the given functional equation are of the form $A^{\psi(x)}$, where $A$ is a constant. A number of generalizations of Cauchy's functional equations found in the mathematical literature are special cases of the one considered here. (Received November 24, 1947.)

\section{4t. Alexander Weinstein: On generalized axially symmetric poten-} tial.

Continuing previous investigation (Bull. Amer. Math. Soc. vol. 53 (1947) p. 59) it is shown that the generalized axially symmetric potential $\phi(x, y)$ $=y^{-q} \int_{0}^{\infty} \exp (-|x| t) J_{q}(y t) J_{q+2 n}(b t) d t ; q>-1 / 2, b>0, n=0,1,2, \cdots$, has a logarithmic singularity at the point $x=0, y=b$. The corresponding stream function is many-valued and has a branch which admits, for $x>0$, the integral representation $\psi(x, y)=-y^{q+1} \int_{0}^{\infty} \exp (-x t) J_{q+1}(y t) J_{q+2 n}(b t) d t$. (Received November 20, 1947.)

\section{5t. Bertram Yood: Banach algebras of bounded functions.}

Let $B$ be the Banach algebra of all bounded complex-valued functions defined on a set $S$. The maximal ideals of $B$ are shown to be in a natural 1-1 correspondence with the two-valued bounded additive set functions defined on the class of all subsets of $S$ and with the maximal additive ideals of the Boolean algebra of subsets of $S$. Maximal ideals of subalgebras of $B$ are investigated. A generalized Weierstrass theorem for such algebras is given. The theory is used to give a proof of Stone's theorem on the topological representation of distributive lattices. (Received November 24, 1947.)

\section{Applied Mathematics}

\section{6t. Garrett Birkhoff: Remarks on streamlines of discontinuity.}

Kreisel, Gilbarg and Rock have obtained the flow pattern for two-dimensional cavity motion past a flat plate, with a reentrant jet, at any cavitation number $K$. The present note relates the cavity drag $D$ with the fluid density $\rho$, the jet crosssection $A^{*}$, the jet velocity $v$, and the free stream velocity $V$, by $D=\rho v(v+V) A^{*}$. This is valid for two-dimensional or axially symmetric three-dimensional flow with reentrant jet, past any symmetric obstacle. If $A$ is the obstacle cross-section, then $C_{D}=2\left(1+K+(1+k)^{1 / 2}\right) A^{*} / A$; if $K=0$, this reduces to $A^{*} / A=C_{D} / 4$. The general volocity relation across a streamline of discontinuity ("stationary slipstream") is shown to be $v^{\prime 2}=A v^{2}+B$, whenever the equations of state have the forms $\rho=k p^{\alpha}$, $\rho^{\prime}=k^{\prime} p^{\prime \alpha}$ on the two sides of the slipstream. Using a formula obtained jointly with $\mathrm{T}$. E. Caywood, the flow pattern for penetration of an incompressible fluid of density $\rho$ by a two-dimensional jet of density $\rho^{\prime}$ is obtained as a special application, with $B=0$. Examples with $B \neq 0$, having circular and spherical slipstreams, are also sketched. (November 13, 1947.)

\section{H. E. Goheen: The critical radius of a heat-generating cylinder.}

Using methods similar to the heuristic methods described in his paper, $A$ nonrigorous suggestion for the solution of certain problems in heat generation, the author discusses a problem in the design of cylindrical catalytic beds. The partial differential equation is $\partial u / \partial t=\partial^{2} u / \partial r^{2}+(1 / r)(\partial u / \partial r)+e^{-1 / u}$ in dimensionless variables. The initial conditions are at $t=0, u=\theta_{0}$ if $r<a$ and $u=\theta_{1}$ if $r>a$. The problem is to de- 
termine a critical radius $A$ such that if $a>A$ overheating occurs, while if $a<A$ it does not. (Received October 29, 1947.)

148t. M. Z. Krzywoblocki. On the boundary layer motion along a periodically oscillating plane in compressible viscous fluid.

The following assumptions are made: the fluid outside the plane at rest is in a periodically oscillating motion (or vice versa, the fluid is at rest and the plane in motion). The flow outside the boundary layer is a potential flow. The following equations were taken into account as concerning the two-dimensional motion in the boundary layer: two equations of motion, equations of continuity, state and energy. The coefficients of viscosity and heat conductivity are assumed to be functions of the temperature only. The solutions are presented as trigonometric series, in which each term may be found by the successive approximation method. By suitably chosen simplifications the nonlinear equations are transformed into linear partial differential equations of the second order with constant coefficients. The first two terms in each series were found, satisfying all the required boundary conditions. (Received November 17, 1947.)

149. P. F. Neményi and R. C. Prim: On helicoidal flow patterns of a perfect gas.

Flow patterns for which the reduced velocity $W$ satisfies the condition $W \times$ curl $W=0$ are discussed with reference to those cases in which the streamlines are coaxial helices. The special case when the consecutive curls satisfy the same condition (curl $W \times$ curl curl $W=0$, and so on) is discussed and leads to a solution in terms of Bessel function. The case when all helices have a common slope and the case when all have a common pitch are also analyzed and the connection of the latter case with the irrotational helicoidal flow of an incompressible fluid discovered by von Laue and Hamel is established. (Received November 20, 1947.)

150t. S. S. Penner and Seymour Sherman: Heat flow through composite cylinders.

A formal solution of the differential equation for a time dependent flow of heat through a composite cylinder is given. The composite cylinder is assumed to be thermally insulated at the outer boundary and to consist of a cylindrical core of one material, initially at the uniform temperature $T_{0}$, surrounded by a cylindrical shell of another material, initially at temperature zero. This work is based on OSRD Report no. 4963 (PB Report no. 50864) On the diffusion of nitroglycerin in wrapped powder grains. The paper appears in the August number of the Journal of Chemical Physics. (Received October 7, 1947.)

151. Harry Polachek: An extension of the method of least squares to systems of ordinary differential equations.

The method of least squares is extended to apply to problems in which the governing relations are given in the form of a system of ordinary differential equations. In such problems, the experimental data may consist of three types of quantities: (a) measured values for the initial conditions to the differential equations, (b) parameters entering in the equations, or (c) values obtained in the solution. The reduction of trajectory data is a good illustration of a problem of this type. A nonlinear system of 
two second order differential equations is involved, which has no known solution in closed form. The experimental information to which this system must be fitted usually consists of the components of the initial velocities (initial conditions) and the final range and time of flight (solution to the differential equations). The problem is to determine certain ballistic coefficients which appear as parameters in the equations. (Received November 20, 1947.)

\section{R. C. Prim: On the existence of steady gas flow in plane iso- thermal streamline patterns.}

An investigation is made of the possibility of a steady plane flow of an ideal gas in the absence of body forces having a streamline pattern which can be mapped conformally onto a family of parallel lines. Irrotationality of the gas flow is not assumed. It is proved that the only possible flows of this type are those having streamlines which are concentric circles, parallel straight lines, or radial straight lines. (Received November 20, 1947.)

153. L. V. Robinson: The solution of partial differential equations by differential operator methods. Preliminary report.

It is shown how all linear partial differential equations, and some nonlinear ones, can be solved by operator methods involving $\exp (g D)$, where the $g$ 's are particular functions of $x, y, z, \cdots$, and where $D \equiv \partial / \partial x, \partial / \partial y, \partial / \partial z, \cdots$. In general these methods are simpler than the usual ones, and Laplace transformations are not necessary to solve second-order linear equations. (Received November 21, 1947.)

154. J. L. Synge: Canonical coordinates for an electro-magnetic field. Preliminary report.

The author deals with an electromagnetic field in vacuo, and the basic idea is to present a relativistic theory without introducing a metric tensor or other structural tensor in space-time. The field is represented by two skew-symmetric covariant tensors $F_{m n}$ and $F_{m n}^{*}$; these correspond respectively to the usual vector pairs $(B, E)$ and $(D, H)$. We can at once write down covariant Maxwellian equations $F_{m n, r}+F_{n r, m}$ $+F_{r m, n}=0$ (the comma denoting partial differentiation), and the same equations with a star, but six equations are still lacking to make the number of equations equal to the number of unknowns. The question discussed is that of the existence of coordinate systems (called canonical) for which $F_{23}^{*}=i F_{14}, \quad F_{31}^{*}=i F_{24}, \quad F_{12}^{*}=i F_{34}, F_{14}^{*}=i F_{28}$, $F_{24}^{*}=i F_{31}, F_{34}^{*}=i F_{12}$. (The presence of the factor $i$ is due to the imaginary character of the fourth coordinate.) The problem breaks into two parts; the first is algebraic, and concerns the existence of coordinates canonical at a point; the second part involves questions of integrability. (Received November 24, 1947.)

\section{C. A. Truesdell: The transport of vorticity.}

The mechanism by which vorticity is transported in the motion of continuous media is discussed in the light of a general kinematic theorem for the rate of change of the total vorticity of a finite volume. The general theorem is first applied to four kinematic situations, one being the infinite region treated originally by Poincare for the special case of plane flow of an incompressible viscous fluid. It is shown that Poincare's theorem, if slightly rephrased, holds in the three-dimensional motion of an arbitrary continuous medium. The general theorem is then applied to the discussion of diffusion of vorticity in a compressible viscous fluid. (Received November 20,1947.) 


\section{A. H. Van Tuyl: The distribution of electricity on two neighbor- ing charged spheres in the presence of an outside point charge.}

In order to study the general problem it is sufficient to consider three special cases. For this investigation, the cases chosen are the following: Two spheres at unit potential when no outside influence acts, two such spheres when the potentials are one and minus one, and two spheres at zero potential in the presence of an outside unit point charge. Without loss of generality, unity and $b$ are taken as the radii. The charge densities are expressed as definite integrals whose integrands contain elliptic functions, and with the aid of these integral representations the charge distributions are studied in the limit as the spheres approach contact. Denoting the distance between the spheres by $\epsilon$, Kirchhoff found that for two spheres of radius unity and potential unity, the charge density at the point of final contact is asymptotically equal to $\pi \epsilon^{-8 / 2} \exp \left[-\pi^{2}\left(2 \epsilon^{1 / 2}\right)^{-1}\right]$. A similar result is found here for two spheres at zero potential in the presence of an outside point charge. Various expansions are found for the limiting charge densities, one of which is a generalization of some expansions given by Poisson. An application of the preceding results is made to the study of circles of equilibrium in the limit. (Received November 20,1947.)

\section{Geometry}

\section{J. M. Clarkson: An irreversible line transformation.}

An arbitrary line $l$ of space meets each of two generators $k_{1}, k_{2}$ belonging to the same regulus $K$ of a quadric surface $S$. These lines $k_{1}, k_{2}$ each meet a ruled cubic surface $C$ in three points at which there are tangent planes to $C$. These triads of tangent planes meet in two points which determine a line $l^{\prime}$. The line $l^{\prime}$ is called the transform of the line $l$ under the line transformation $T$. The irreversibility of $T$, the order of $T$ and the singular lines of $T$ are discussed. (Received December 16, 1947.)

\section{N. A. Court: Skewly cevian tetrahedrons.}

If a tetrahedron $\left(T^{\prime}\right)=A^{\prime} B^{\prime} C^{\prime} D^{\prime}$ is inscribed in a tetrahedron $(T)=A B C D$ and the lines $A A^{\prime}, B B^{\prime}, C C^{\prime}, D D^{\prime}$ form a hyperbolic group, the tetrahedron $\left(T^{\prime}\right)$ may be said to be skewly cevian to, or for, $(T)$. The lines $A A^{\prime \prime}, B B^{\prime \prime}, C C^{\prime \prime}, D D^{\prime \prime}$ passing through the vertices of $(T)$ and meeting the lines $A A^{\prime}, B B^{\prime}, C C^{\prime}, D D^{\prime}$ form a second hyperbolic group whose traces in the faces of $(T)$ are the vertices of a second tetrahedron $\left(T^{\prime \prime}\right)=A^{\prime \prime} B^{\prime \prime} C^{\prime \prime} D^{\prime \prime}$ which is also skewly cevian to $(T)$. The two tetrahedrons $\left(T^{\prime}\right),\left(T^{\prime \prime}\right)$ may be said to constitute a twin pair of skewly cevian tetrahedrons for $(T)$. The feet of the twelve cevians of the four vertices of $\left(T^{\prime}\right)$ for the respective faces of $(T)$ coincide with the twelve analogous points obtained for the vertices of $\left(T^{\prime \prime}\right)$. These twelve points lie on a quadric surface. The lines joining corresponding vertices of a twin pair of skewly cevian tetrahedrons $\left(T^{\prime}\right),\left(T^{\prime \prime}\right)$ form a hyperbolic group. The anharmonic ratio of these four hyperbolic lines is equal to that of the pencil of lines $T^{\prime \prime}\left(T^{\prime} A B C\right)$ in the plane $A B C$. (Received November 17, 1947.)

159. G. B. Huff: Diophantine problems in geometry and elliptic ternary forms.

Several diophantine problems in elementary geometry are equivalent to the determination of the rational solutions of the elliptic cubic $C: \alpha z_{1}\left(z_{2}^{2}-z_{3}^{2}\right)=b z_{2}\left(z_{1}^{2}-z_{3}^{2}\right)$. It is shown that any elliptic cubic with coefficients in a field $k$ of algebraic numbers and possessing a certain configuration of eight points may be represented by $C$. The 
theory of $C$ is developed by the methods of Hurwitz and Mordell. Certain nonexistence theorems are proved when $k$ is the field of rational numbers and applications are made to the problems in geometry. (Received November 7, 1947.)

\section{0t. M. O. Reade: Extension to minimal surfaces of a theorem of Lindelöf.}

Let $f_{j}(z)$ be analytic for $|z|=|u+i v|<1$ and continuous for $|z| \leqq 1, j=1,2,3$, and let $\sum_{j=1}^{z}\left[f_{j}^{1}(z)\right]^{2}=0$. Then the surfaces $S: x_{j}=R f_{j}(z)$ and $S^{*}: y_{j}=1 f_{j}(z), j=1,2,3$, are adjoint minimal surfaces given in isothermic representation. Then an extension of a result due to Lindelöf (4th Scandinavian Mathematical Congress, Stockholm, 1916, pp. 59-90) is the following theorem. If the boundaries of $S$ and $S^{*}$ are Jordan curves, and if these curves have tangents at the respective images of $z=e^{i \theta_{0}}$, then the mappings from $|z| \leqq 1$ to $S$ and $S^{*}$ remain isogonal-in the wide sense-for $z=e^{i \theta}$. Applications of this extension are considered. (Received November 24, 1947.)

161. E. B. Shanks: Homothetic correspondences between Riemannian spaces of two dimensions.

Necessary and sufficient conditions (in terms of invariants) that there exist a homothetic correspondence between two Riemannian spaces of two dimensions are obtained. The sufficient conditions are deduced from a lemma which states the conditions for $a$ to be a constant when two such spaces have linear elements in the relation $\tilde{g}_{i j}(u, v)=e^{2 a} g_{i j}(u, v)$. The lemma makes it possible to state the necessary and sufficient conditions without the use of an arbitrary constant. (Received November 20, 1947.)

\section{Statistics and Probability}

\section{A. C. Cohen: Generalized $I_{n}$ functions.}

The relations $I_{0}(\xi)=\int \xi \psi(t) d t$ and $I_{n}(\zeta)=\int_{\zeta}^{\xi} I_{n-1}(\xi) d t$, where $\psi(t)$ is an unspecified frequency function characterized by parameters $\alpha, \beta, \gamma, \cdots$, define a set of functions which are related to the moments of a general class of truncated frequency distributions. $\psi(t)$ is defined over the range $r \leqq t \leqq s$, and $\zeta$ is any value of $t$ within this range. If $\psi(t)=\left(1 / 2 \pi^{1 / 2}\right) e^{-t^{2} / 2}$, these functions become those used by R. A. Fisher (Introduction to mathematical tables, vol. 1, British Association for the Advancement of Science, 1931, pp. 26-35) in connection with his solution of truncated normal distributions. Properties of the general $I_{n}$ functions are investigated, and it is shown how they might be employed in solutions of multi-parameter truncated frequency distributions. Differential and difference equations satisfied by these functions are developed for two cases in which $\psi(t)$ assumes the forms $\psi(t)=t^{\alpha} e^{-t}$ and $\psi(t)=(1-t)^{\alpha}(1+t)^{\beta}$ respectively. R. A. Fisher previously stated similar results when $\psi(t)$ is the normal frequency function. (Received November 14, 1947.)

163t. Aryeh Dvoretzky: On smoothing through repeated averaging. Preliminary report.

Let $\left\{A_{n}\right\}(n=0, \pm 1, \pm 2, \cdots)$ be a statistical distribution sequence, that is, $A_{n} \geqq 0$ for all $n$ and $\sum A_{n}=1$. Let $k$ be a positive integer and put $A_{n}^{(0)}=A_{n}$, $A_{n}^{(m+1)}=\left(\sum_{\nu=-k}^{k} A_{n+v}^{m}\right) /(2 k+1)$. It was proved by E. Slutsky (Econometrica vol. 5 (1937)) and by M. Faesi (Mitteilungen der Vereinigung Schweitzerischer Versicherungs Mathematiker vol. 40 (1940)) that under certain restrictions the points 
$\left(n / m^{1 / 2}, m^{1 / 2} A_{n}^{(m)}\right)$ approach, as $m \rightarrow \infty$, the curve $\left(^{*}\right) y=\left(h / \pi^{1 / 2}\right) e^{-h^{2} x^{2}}$ where $h=3 /\left(2 k^{2}+2 k\right)$. Using simple results of the theory of probability it is easily established that the above result subsists without any restrictions (other than $A_{n} \geqq 0$, $\sum A_{n}=1$ ). Indeed, the same result holds even when the averaging process is replaced by $A_{n}^{(m+1)}=\sum_{\nu-k}^{k} g_{\nu} A_{n+\nu}^{(m)}$ with $g_{\nu} \geqq 0, \quad \sum_{-k}^{k} g_{\nu}=1, \sum_{-k}^{k} g_{\nu}=0$, provided we replace $h$ in $\left(^{*}\right)$ by $1 /\left(2^{-1} \sigma\right)$ where $\sigma^{2}=\sum_{-k}^{k} \nu^{2} g_{\nu}$. Moreover, $\left\{g_{\nu}\right\}$ may even be an infinite sequence provided it satisfies some weak conditions. The sequence $\left\{g_{\nu}\right\}$ may be replaced by a sequence of sequences $\left\{g_{\nu}^{(m)}\right\}$. Analogous results can be obtained for the averaging of continuous functions. (Received November 24, 1947.)

164t. Kenneth May: Variation of the probability of unfair election results. Preliminary report.

The paper continues a previous study (Bull. Amer. Math. Soc. Abstract 53-9346) by dropping the assumption of uniform distribution of outcomes in the districts. Let $x_{i}$ be the vote of one party in the $i$ th district and let $x_{i}$ for all $i$ follow the law given by $p_{x}(x=0,1, \cdots, m$ where $m=2 \mu-1)$. Let $y_{i}=0$ when $x_{i}<m / 2$ and $y_{i}=1$ when $x_{i}>m / 2$. Assume $\epsilon\left(x_{i}\right)=m / 2$ and $\epsilon\left(y_{i}\right)=1 / 2$. Then as the number of districts becomes large, the probability of an unfair result approaches $P(m, \infty)=1 / 2$ $-(1 / \pi) \arctan \left\{R /\left(1-R^{2}\right)^{1 / 2}\right\}$, where $R$ is the correlation coefficient of $x_{i}$ and $y_{i}$. Consider the variation of $R$ and hence of $P(m, \infty)$ with variations in the $p_{x} . R$ has no relative extrema in the region of interest. It attains an absolute maximum of 1 when for some $k, p_{k}=p_{m-k}=1 / 2$. Its absolute minimum, $2 m^{1 / 2} /(m+1)$, is attained at the single point given by $p_{0}=p_{m}=1 / 2(m+1), p_{\mu-1}=p_{\mu}=m / 2(m+1)$, and all other $p_{x}$ equal to zero. With varying frequency distributions the probability of an unfair result ranges from zero to a maximum which approaches $1 / 2$ as $m \rightarrow \infty$. (Received November 17, 1947.)

\section{5t. G. R. Seth: The variance of sequential estimates.}

Let $X_{1}, X_{2}, \cdots$ be a sequence of chance variables whose distribution depends upon an unknown parameter $\theta$ and possibly also on a finite number of other parameters. Assume that the $X$ 's are either absolutely continuous or take only discrete values and let $p_{n}\left(x_{1}, x_{2}, \cdots, x_{n}, \theta\right)$ denote either the probability density or the probability. Let a sequential process be given, and the chance variable $n$ be the number of observations. Let $\theta^{*}\left(n_{1}, n_{2}, \cdots, n_{n}\right)$ be an unbiased estimate of $\theta$ and write $\phi_{i n}=\left(1 / p_{n}\right) \partial^{i} p_{n} / \partial \theta^{i}$. Finally let $\lambda_{i j}$ be the covariance between $\phi_{i n}$ and $\phi_{i n}$ and $\left[\lambda^{i j}\right]=\left[\lambda_{i j}\right]^{-1}(i, j=1,2,3, \cdots, m)$. Under certain regularity conditions and the linear independence of $\phi_{\text {in }}$ the author proves $\sigma^{2}\left(\theta^{*}\left(x_{1}, x_{2}, \cdots, x_{n}\right)\right) \geqq \lambda^{11}$. This lower bound is not less than the lower bound $K$ obtained by Wolfowitz (Ann. Math. Statist. (1947)). If and only if for some integer $i(i \geqq 2) \lambda_{i 1} \neq 0$, then $\lambda^{11}>K$. The latter is true, for example, in some very important Wald sequential tests. When $\theta^{*}\left(x_{1}, x_{2}, \cdots, x_{n}\right)$ is a biased estimate, that is, $E\left[\theta^{*}\left(x_{1}, x_{2}, \cdots, x_{n}\right)\right]=\theta+b(\theta)$, then $\sigma^{2}\left(\theta^{*}\right) \geqq \sum_{i=1}^{m} \sum_{j=1}^{m} \lambda^{i j}\left(d^{i}(b(\theta)+\theta) / d \theta^{i}\right)\left(d^{i}(b(\theta)+\theta) / d \theta^{j}\right)$. (Received October 23, 1947.)

166t. W. R. Thompson: Direct probability sequential analysis. Preliminary report.

The general subject of sequential analysis was broached elsewhere with illustrations of systematically associated apportionment (Biometrika vol. 25 (1933) p. 285; Amer. J. Math. vol. 57 (1935) p. 450; Annual APHA Meeting, October 8, 1947). Also, it was shown that if $\phi$ is the unknown probability that $x$, a random element of 
$U$, be less than a constant $c$, and if $\left\{x_{i}\right\}$ is a random sample of $n$ observed values, only one of which may equal $c$, and $a$ of them are above and $b$ below; then, for $0<p<1$, $I_{p}(b+1, n-b) \leqq \bar{P}(\phi<p) \leqq I_{p}(n-a, a+1)$. Thus if $0<p^{\prime} \leqq p^{\prime \prime}<1$ and $\alpha$ and $\beta$ are fixed tolerable risks, then $U$ may be classified as in $A, B$, or $C$ according as data shows: $\bar{P}\left(\phi<p^{\prime}\right) \leqq \alpha ; \bar{P}\left(\phi>p^{\prime \prime}\right) \leqq \beta$; or otherwise, whereupon another observation is taken. This process will end with $U$ in either $A$ or $B$ for some $n$ not exceeding a predeterminable $n_{0}$ provided $p^{\prime} \neq p^{\prime \prime}$. Risks approximate $\alpha$ and $\beta$, respectively, for decisions made at any stage, the acceptance numbers depending respectively on $\left(p^{\prime}, \alpha\right)$ or $\left(p^{\prime \prime}, \beta\right)$ only. These properties contrast favorably with those of corresponding probability-ratio sequential tests. (Received November 17, 1947).

\section{TOPOLOGY}

\section{7t. Mariano García and G. A. Hedlund: The structure of minimal} sets.

A minimal set $M$ is a topological space $X$ acted on by a transformation group $T$ such that the orbit closure of every point of $X$ coincides with $X$. Let $M$ be a minimal set for which $X$ is a compact metric space and $T$ is an abelian topological group. The subgroup $G$ of $T$ is relatively dense in $T$ if there exists a compact subset $C$ of $T$ such that $T=G+C$. The orbit closure under $G$ of a point of $X$ may or may not coincide with $X$. It is shown that the orbit closures under $G$ constitute a continuous decomposition of $X$. Several of the possibilities with regard to the totality of decompositions obtained by consideration of all relatively dense subgroups of $T$ are analyzed. There is displayed an example of a regularly almost periodic point such that not all points in the orbit closure are regularly almost periodic. (Received October 23, 1947.)

\section{8t. W. H. Gottschalk. Transitivity and equicontinuity.}

A group of homeomorphisms on a topological space is called algebraically (topologically) transitive in case the orbit (orbit-closure) of some point of the space is the space. The following theorem is proved: If $X$ is a compact metric space, if $G$ is a topologically transitive abelian group of homeomorphisms on $X$ and if $H$ is the group of all homeomorphisms on $X$ which commute with every element of $G$, then the following statements are pairwise equivalent: (1) $H$ is algebraically transitive; (2) $H$ is equicontinuous; (3) $G$ is equicontinuous. (Received November 24, 1947.)

\section{W. H. Gottschalk and G. A. Hedlund: Dynamics of trans- formation groups.}

Let $X$ be a topological space, $T$ an abelian topological group, and $f$ a continuous transformation of the Cartesian product $X \times T$ onto $X$. If $x \in S$ and $t \in T$, denote the image under $f$ of $x \times t$ by $x t$. Assume that $T$ is a transformation group acting on $X$ in the sense that (a) $x e=x$ if $x \in X$ and $e$ is the identity in $T$, and (b) $(x s) t=x(s t)$ if $x \in X$ and $s, t \in T$. The semigroup $S$ in $T$ is replete if, $C$ being any compact set in $T$, an element $t \in T$ exists such that $C t C S$. The subset $B$ of $T$ is extensive if $B$ intersects every replete semigroup in $T$. The group $T$ is recurrent at $x$ if, corresponding to any neighborhood $U$ of $x$, there exists an extensive set $B$ in $T$ such that $x B C U$. The group $T$ is regionally recurrent (nonwandering) at $x$ if, corresponding to any neighborhood $U$ of $x$, an extensive set $B$ in $T$ exists such that $b \in B$ implies $U \cap U b \neq \varnothing$. The group $T$ is permissible if it is locally compact and contains a compact generating system. In this paper the properties of recurrence are developed in detail and in par- 
ticular it is shown that if $X$ is metrizable and $T$ is separable, permissible and pointwise regionally recurrent, then the set of recurrent points is a $G_{\delta}$ set residual in $X$. This is the topological analogue of the Poincare recurrence theorem. (Received November 24,1947 .)

\section{0t. S. T. Hu: Mappings of a normal space into an absolute} neighborhood retract.

The author generalizes the theorems of Eilenberg (Ann. of Math. vol. 41, p. 231, vol. 42, p. 459) to the mappings of a normal space into an ANR and to the homotopy type of compact ANR. The chief methods which he used are his fundamental bridge theorems. A bridge of a mapping $f: X \rightarrow Y$ is a finite open covering $\alpha$ such that there exists a mapping $\psi$ of the nerve $A$ into $Y$ and a canonical mapping $\phi: X \rightarrow A$ such that $\psi \phi$ is homotopic with $f$. Every mapping of a normal space into an ANR has a bridge, and every refinement of a bridge is also a bridge. Further, for any two bridges of the mapping $f$, the mappings in the definition of bridge satisfy some homotopy relations. By means of the bridge operation and Cech cohomology theory, he carries out the said generalizations. (Received November 24, 1947.)

\section{F. B. Jones: Concerning non-aposyndetic continua.}

Let $M$ be a compact, metric continuum. A point $p$ of $M$ is said to be a weak cut point of $M$ if $M-p$ is not strongly (continuum-wise) connected. It is shown that if $M$ is not semi-locally-connected at any point of an open subset $U$ of $M$, then $U$ contains a weak cut point of $M$. Now suppose that $M$ is cyclic (that is, $M$ contains no separating point). G. T. Whyburn has shown that if $M$ is semi-locally-connected, then $M$ contains no weak cut point. The converse is not true. It is shown, however, that if $M$ contains no weak cut point, then the set of points at which $M$ is both aposyndetic and semi-locally-connected is a dense inner-limiting subset $\left(G_{\delta}\right.$-set) of $M$. (Received November 24, 1947.)

\section{2t. F. I. Mautner: Decomposition of unitary representations of} groups. Preliminary report.

Using von Neumann's theory of generalized direct sums (=direct integrals) of Hilbert spaces and rings of operators it is proved that any self-adjoint family of bounded operators in a separable Hilbert space is generalized direct sum of irreducible families, that is, families which do not leave any proper linear closed subspaces invariant. It follows that any unitary representation of a group is generalized direct sum of irreducible unitary representations. Corollary: If $U$ is any faithful unitary representation of a locally compact group $G$ in a separable Hilbert space then the irreducible components of $U$ form a separating system of irreducible unitary representations of $G$. (Cf. Gelfand and Raikov, C. R. (Doklady) Acad. Sci. URSS. vol. 42 (1944) pp. 199-201.) Also I. E. Segal's existence of irreducible representations of operator algebras follows (Bull. Amer. Math. Soc. vol. 53 (1947) pp. 73-88). The above results are applied to a generalization of the Peter-Weyl theory to arbitrary locally compact separable groups. (Received November 25, 1947.)

173. A. N. Milgram: Isomorphisms of the semigroup of continuous functions on a bicompact Hausdorff space. 
Let $S$ be a bicompact Hausdorff space and $C$ the set of continuous functions defined on $S$. $C$ is regarded as a semigroup under multiplication (that is, $f \cdot g(x)=f(x) \cdot g(x)$ for each $x \in S$ ). It is shown that two spaces with isomorphic semigroups are homeomorphic. This is used to prove that if $S$ is connected then the automorphisms $\sigma$ of $C$ (that is, 1-1 mappings $\sigma$ of $C$ on $C$ such that $\sigma(f \cdot g)=\sigma f \cdot \sigma g$ ) must have a particularly simple form. For each such automorphism $\sigma$ there exists a homeomorphism $H$ of $S$ on $S$ and a continuous nowhere zero function $p(x)$ defined for $x \in S$ as $\sigma f(x)= \pm|f(H(x))| p(x)$ where the sign \pm is the same as that of $f(H(x))$. (Received December 30,1947.)

174t. G. D. Mostow: On the extensibility of local Lie groups of transformations and groups of the plane. Preliminary report.

Let $G: R$ denote a local transitive Lie group of transformations (cf. Pontrjagin, Topological groups, p. 286) defined in an open set $R$ of an $n$-dimensional manifold. If $G$ is a global group and the transformations of $G: R$ are defined and transitive on all of $R$, then $G: R$ is called a "global transitive group of transformations." Theorem. Let $G$ be a local Lie group and $U_{n}$ a Euclidean $n$-dimensional neighborhood. If $n<5, G: U_{n}$ can be extended to a global transitive group of transformations $\bar{G}: M_{n}$ over a manifold $M_{n}$, that is, there is a local isomorphism between $G: U_{n}$ and $\bar{G}: M_{n}$. If $n \geqq 5$, the theorem is not true. Equivalent to this theorem is the following: Any $(r-k)$-dimensional Lie subgroup of a simply connected $r$-dimensional Lie group is closed, if $k<5$. All global Lie transitive groups of transformations on (2-dimensional) surfaces are determined and also all surfaces on which global Lie transitive groups of transformations act. The surfaces are the plane, cylinder, torus, sphere, projective plane, möbius strip, and Klein bottle. (Received November 15, 1947.)

\section{J. H. Roberts: Open transformations of Peano continua.}

Suppose that $f(A)=B$, where $f$ is an open transformation (continuity is not assumed), and $f$ is at most $k$-to-1, for some integer $k$. Then if $A$ is a Peano continuum which contains no continuum of condensation, and $B$ is any compact continuum, it follows that $B$ is actually a Peano continuum. This permits a strengthening of a theorem by Rhoda Manning (Duke Math. J. vol. 13 (1946) pp. 179-184). Other theorems are developed, with the aim of characterizing all possible compact connected images of a linear graph under at most $k$-to-1 open transformations. (Received November 24, 1947.)

\section{H. D. Ursell and L. C. Young: Remarks on the theory of prime ends. I.}

The beautiful theory of prime ends of a simply-connected plane domain $D$, conceived by Caratheodory some thirty-five years ago, has hardly been touched by subsequent advances in plane topology. For instance, their relation to the other complementary domains of the boundary of $D$ has not previously been studied. The results established by the present writers include: "I. Let $X$ be a prime end of a domain complementary to the boundary $B$ of $D$. Then there exist two prime ends $Y, Z$ of $D$ which together include each point of $X$." "II. Let $\left\{D_{n}\right\}$ be the domains complementary to a bounded continuum $W$ and suppose given in $W$ a system of subcontinua called 'links,' each of which meets at least 3 prime ends of the same or different domains $D_{n}$. Then there exists an enumerable selection $\left\{X_{k}\right\}$ of prime ends of the various $D_{n}$ and an enumerable selection $\left\{\Lambda_{k}\right\}$ of the given links, such that every link of the given system meets at least one $X_{k}$ or $\Lambda_{k}$." As a corollary, when links are single 
points: "The boundary points of multiplicity not less than 3 of $D$ lie on a certain enumerable selection of the prime ends of $D . "$ (Received November 21, 1947.)

177t. H. D. Ursell and L. C. Young: Remarks on the theory of prime ends. II.

In a prime end, Caratheodory distinguished between principal points and subsidiary points. The authors distinguish further between two halves of a prime end (each half containing the principal points but not necessarily all subsidiary points) and obtain: "III. Let $x, y$ be two points of a same half of a prime end of $D$. Then the boundary $B$ of $D$ contains a sequence $\left\{K_{n}\right\}$ of disjoint continua such that (a) the distances $\rho\left(x, K_{n}\right), \rho\left(y, K_{n}\right) \rightarrow 0$ as $n \rightarrow \infty$; (b) given $\delta>0$, there exist $n_{0}$ so that each subcontinuum $C$ of $B$ with both distances $\rho(x, C), \rho(y, C) \geqq \delta$ meets at most one $K_{n}$ where $n>n_{0}$." As an application of III it follows, for instance, that: "IV. Let $\phi(w)$ be a continuous vector function for $w$ in $B$ whose values are points of Euclidean space, and suppose that $\phi(w)$ is not constant on a certain prime end of $D$. Then $B$ contains a sequence $W_{n}$ of disjoint continua, no two of which meet a same subcontinuum of constancy of $\phi(w)$ in $B$, such that $\sum_{n} \operatorname{osc}\left(\phi, W_{n}\right)=+\infty$." This requires that whenever $B$ is transformed continuously into a system whose length (suitably defined) is finite, the prime ends are transformed into single points. A number of further results are also obtained by defining a certain "order of priority" of the points on each half of a prime end. (Received November 21, 1947.)

\section{8t. A. D. Wallace: Continua invariant under solvable groups.}

Let $X$ be a Hausdorff continuum, $Z$ a topological group and $f$ a map of $Z \times X$ into $X$ such that $f(x, e)=x$ (e the neutral element of $Z$ ) and $f\left(z, f\left(z^{\prime}, x\right)\right)=f\left(z z^{\prime}, x\right)\left(z, z^{\prime} \in Z\right)$. Define $z(x)$ as $f(z, x)$ so that $z$ is a homeomorphism of $X$ onto $X$. It is shown that, if $Z$ is solvable, there exists a prime chain ( $=$ cyclic element when $X$ is metric and locally connected) which is invariant under each element of $Z$. This had previously been shown when $Z$ is Abelian or finite. (Received November 3, 1947.)

\section{A. D. Wallace: The fundamental group as a Galois group.}

Let $X$ be a Hausdorff space satisfying certain local regularity conditions and which is compact. Let $Y$ be the universal covering space for $X$ of $f$ the natural map of $X$ onto $Y$ so that $f$ is a uniform local homeomorphism. Denote by $C(X), C(Y)$ the ring of continuous real functions on $X, Y$. Then $f$ determines an isomorphism of $C(Y)$ into $C(X)$. Let $C_{0}$ be the image of $C(Y)$. Finally denote by $G(X)$ the Galois group of $C(X)$ over $C_{0}$. Under rather stringent conditions it is shown that $G(X)$ is an isomorph of the fundamental group of $X$. This result points the way toward possibly interesting generalizations of the fundamental group. There does not seem to be an obvious and simple extension of this to the Hurewicz groups. (Received November 3, 1947.)

\section{J. R. KLINE,} Secretary 


\section{APPENDIX}

\section{EXCERPTS FROM REPORT OF TREASURER}

December 15, 1947

To THE BOARD OF TRUSTEES OF THE American Mathematical Society

Gentlemen:

I have the honor to submit herewith the report of the Treasurer for the fiscal year ended November 30, 1947, with such comments as have become customary.

\section{Investment Portfolio}

On November 30,1947, the market value of securities held for Invested Funds exceeded book value by $\$ 6,508$, and the market value of securities held for Current Funds exceeded book value by $\$ 94$. In view of these figures and of the large amount of U. S. Government bonds in the portfolio, the reserves held in accounts "Reserve for Investment Losses" and "Profit on Sales of Securities" may still be considered adequate protection against contingent depreciation in market value.

The following is a summary of the changes in security holdings made during the year.

Acquired by Purchase:

40 shares American Can Co. com.

100 shares Crane Co. com.

35 shares Radio Corp. of America cum. pfd.

50 shares Union Oil of California $\$ 3.75$ cum. pfd.

25 shares Northern States Power Co. of Minnesota $\$ 3.60$ cum. pfd.

10 shares Bethlehem Steel 7\% pfd.

30 shares Aetna Insurance Co. cap.

20 shares Texas Co. cap.

Sold or Recalled:

100 shares Sears Roebuck and Co. com.

30 shares Firestone Tire and Rubber Co. $4 \frac{1}{2} \%$ cum. pfd.

50 shares Tidewater Associated Oil Co. $\$ 3.75$ cum. pfd.

The investment portfolio, valued at market November 30, 1947, now includes Government bonds 36.7 per cent, other bonds 7.7 per cent, preferred stock 12.9 per cent, common stock 37.4 per cent, cash in savings bank 5.3 per cent. 


\section{Income from Investments}

Income received during the year from investment of Current Funds amounted to $\$ 2,231$, exclusive of $\$ 95$ earmarked for International Congress. This represents a return of 2.8 per cent computed on average book value of investments. Income on Invested Funds amounted to $\$ 7,837$, representing a return of 4.0 per cent. Total investment income from all sources was $\$ 10,163$, representing a return over 3.6 per cent. These rates of return are higher than in 1946.

Income from the Henderson Estate was $\$ 4,850$; in 1946 it was $\$ 4,800$.

\section{Changes in Net Assets}

Net assets increased by $\$ 2,655$ during the year. In interpreting this figure, it should be noted that among the receipts is a net amount of $\$ 3,225$ for account of the Birkhoff Memorial Project. Except for this item net assets would have shown a decrease even though a bequest of $\$ 1,000$ from the Estate of Mrs. J. I. Hutchinson is included among the receipts, as well as $\$ 1,903$ net profit received from sales of securities during the year. Furthermore over $\$ 23,000$ of assets represent reserves designated toward the publication of six volumes (other than the Birkhoff Papers) which are in process, and whose cost is expected to be not less than $\$ 30,000$. Difficulties in the printing industry are the sole reason that substantial payments have not been made from these reserves.

\section{Decrease in Surplus}

Surplus account for the first time in many years shows a decrease of $\$ 6,878$, and it has been necessary to draw upon savings accounts for funds to meet expenses. For this, heavily increased printing costs for Bulletin and Transactions were largely responsible, though additional salary expense to meet increasing demands for clerical assistance played a part. Also, it became necessary to rent additional office space in New York, and finally, during the year the Rockefeller Foundation felt obliged to discontinue their generous grants toward the expenses of the Policy Committee. On the income side, receipts from dues were somewhat more than in the previous year, as were initiation fees. A high volume of publication sales was maintained, even though stocks of books have been undesirably short. But even with increased investment income the gains were not sufficient to balance increased general disbursements. 


\section{Mathematical Reviews}

For the second consecutive year, operation of Mathematical Reviews resulted in a deficit, this time of $\$ 5,782$, although receipts for this account exceed expectations by some $\$ 2,700$. Again, the heavily increased printing costs were a principal factor. A contract with the Office of Naval Research, Department of the Navy, negotiations for which are just being completed, is expected to provide funds accrued in the fiscal year 1947 which will wipe out this deficit. This contract is to cover the editorial expenses for Mathematical Reviews until March, 1949.

I trust that these remarks may prove helpful to the Board in planning financial policies for the next fiscal year.

Respectfully submitted, Bennington P. GiLl, 


\section{BALANCE SHEET}

\begin{tabular}{|c|c|c|}
\hline Assets & $\begin{array}{c}\text { November } \\
30,1947\end{array}$ & $\begin{array}{c}\text { November } \\
30,1946\end{array}$ \\
\hline \multicolumn{3}{|l|}{ Current Funds: } \\
\hline & $\$ 16,315.50$ & $\$ 26,130.60$ \\
\hline \multirow[t]{2}{*}{ 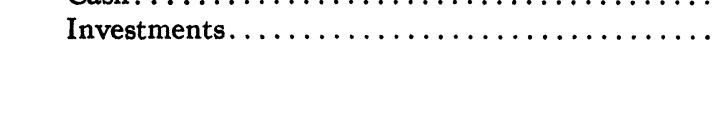 } & $70,559.50$ & $60,837.08$ \\
\hline & $\$ 86,875.00$ & $\$ 86,967.68$ \\
\hline \multirow{4}{*}{ 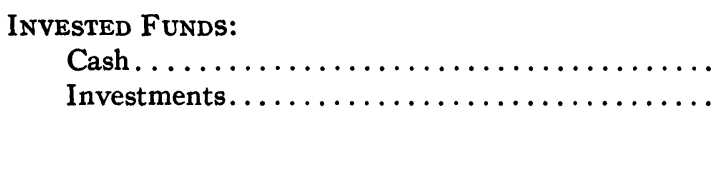 } & & \\
\hline & $\$ 1,287.90$ & $\$ \quad 652.40$ \\
\hline & $194,987.15$ & $192,874.73$ \\
\hline & $\$ 196,275.05$ & $\$ 193,527.13$ \\
\hline Total As & $\$ 283,150.05$ & $\$ 280,494.81$ \\
\hline
\end{tabular}

Current Funds:

\section{Liabilities}

Mathematical Reviews..................

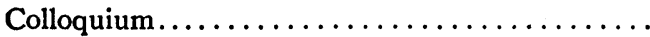

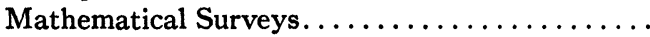

Symposia on Applied Mathematics............

Birkhoff Memorial Project................

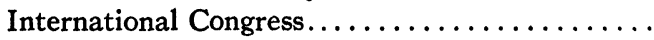

Committee on Aid to Devastated Libraries.....

Policy Committee.....................

Prize Funds and Other Special Funds Accumulated

Income.

$$
\begin{array}{r}
1,897.50 \\
11,708.12 \\
3,734.70 \\
2,700.00 \\
3,061.68 \\
6,413.49 \\
1,320.50
\end{array}
$$

$\$ 7,389.34$

$9,495.90$

$1,796.87$

$6,321.92$

913.34

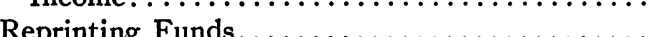

Sinking Fund

Profit on Sales of Securities.................

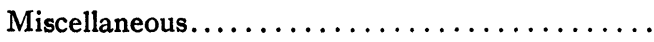

Surplus.............................

INVESTED FuNDS:

Endowment Fund Principal...............

\begin{tabular}{|c|c|}
\hline $\begin{array}{r}6,848 \cdot 12 \\
6,165 \cdot 74 \\
1,044.54 \\
982.60 \\
300.45 \\
40,697.56\end{array}$ & $\begin{array}{r}5,591.42 \\
5,780.67 \\
960.65 \\
982.60 \\
159.24 \\
47,474.73\end{array}$ \\
\hline $86,875.00$ & $86,967.6$ \\
\hline $\begin{array}{r}71,000.00 \\
32,033.22 \\
3,407.61 \\
5,000.00 \\
65,000.00 \\
4,385.89 \\
15,448.33\end{array}$ & $\begin{array}{r}71,000.00 \\
31,033.22 \\
3,563.40 \\
5,000.00 \\
65,000.00 \\
4,385.89 \\
13,544.62\end{array}$ \\
\hline 96,275 & $193,527.13$ \\
\hline & \\
\hline
\end{tabular}

Prize Funds and Other Special Funds..........

Life Membership and Subscription Reserve.....

Colloquium..........................

Mathematical Reviews.

Reserve for Investment Losses... . . . . . . . . . . . .

Profit on Sales of Securities.

TOTAL Liabilities. 


\section{SUMMARY STATEMENT OF INCOME AND EXPENDITURES \\ 1946-1947}

\section{GENERAL RECEIPTS:}

Dues-Ordinary Memberships.

Dues-Contributing Memberships........

Dues-Institutional Memberships...........

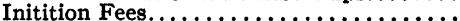

Investment Income...

Miscellaneous

Grant from Rockefelier Foundation for Policy Committee................

${ }^{19}$
Receipts
$\$ 21,628.19$
931.86
$8,011.63$
$1,195.10$
$11,055.52$
288.19
$1,500.00$

1947 Disburse-
ments

General Disbursements:

Treasurer $\ldots \ldots \ldots \ldots \ldots \ldots \ldots \ldots \ldots \ldots$

Treasurer $\ldots \ldots \ldots \ldots \ldots \ldots \ldots \ldots$

Furniture and Fixtures $\ldots \ldots \ldots \ldots \ldots \ldots \ldots$

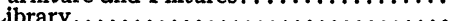

Policy Committee.

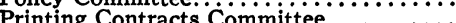

Committee on Aid to Devastated Libraries.

Rent-Editorial Office..............

Emergency.....................

Total.

Excess of General Receipts.

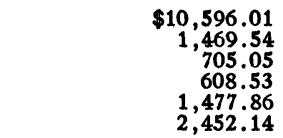

,452.14

$2,068.22 \quad 747.72$

305.32

65.33

$\overline{\$ 46,678.71} \overline{\$ 18,427.50}$

$\$ 28,251.21$

$\$ 44,636.17$

$\$ 30,966.33$

$\$ 7,372.96$

$1,200.37$

629.56

601.14

$1,473.46$

$2,229.91$

41.20

120.65

$\$ 13,669.84$

$3,179.61$

$\$ 21,940.26$ 486.11

846.51

$7,397.86$

$1,517.05$

$8,135.42$

$19,817.73$

$2,489.12$

$3,225.32$

93.15

$13,065.22$

$1,492.38$

$5,923.20$

$25,309.57$ 551.29

163.64

9.26

Birkhoff Memorial Project.

$2,700.00$

$2,250.00$

Symposium on Applied Mathematics.....

American Journal. . . . . . . . . . .

Library Catalogue. . . . . . . . . . . .

Total.

$\frac{\overline{\$ 49,401.77} \overline{\$ 71,190.93}}{\$ 21,789.16}$

$\$ 2,498.87 \quad \$ 16,425.94$

928.75

$7,114.07$

$1,541.68$

$5,829.18$

$17,365.28$

$10,215.58$

$5,644.08$

$23,613.28$

75.59

147.71

7.97

$2,500.00$

$1,868.68$

$\$ 36,047.05$

$\$ 60,351.12$

$\$ 24,304.07$

Excess Cost of Publication..........

OTHER:

Special Funds (including Congress)....... Profit/Loss on Sales of Securities............ Miscellaneous . Surplus:

Mathematical Reviews............. Mathematical Surveys ................ Symposium on Applied Mathetated Li Combree on Ald to Devastated Li-

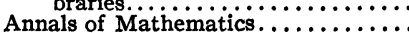

Total

Difference.

$\$ 2,351.87$

$1,903.71$

3.60

$\$ 1,267.91$

$\$ \quad 204.39$

141.21

67.64

$1,000.00$

$1,000.00$

$2,000.00$

$\begin{array}{r}\begin{array}{r}1,500.00 \\ 1,000.00\end{array} \\ \hline \$ 4,396.79 \$ 8,203.60 \\ \hline \$ 3,806.81\end{array}$

$\begin{array}{r}\begin{array}{r}1,500.00 \\ 1,000.00\end{array} \\ \hline \$ 4,396.79 \$ 8,203.60 \\ \hline \$ 3,806.81\end{array}$

$\$ 2,655.24$

$\$ 3,806.81$

$\$ 2,358.77 \$ 1,204.39$

Net Change in Assets..........

$\$ 7,816.64$

ASSETS BEGINNING OF YEAR. . . . . . . . . 